\title{
biomolecules
}

ISSN 2218-273X

www.mdpi.com/journal/biomolecules/

Article

\section{Mammalian Cell Surface Display as a Novel Method for Developing Engineered Lectins with Novel Characteristics}

\author{
Keisuke Soga ${ }^{1}$, Hirohito Abo ${ }^{1}$, Sheng-Ying Qin ${ }^{1}$, Takuya Kyoutou ${ }^{1}$, Keiko Hiemori ${ }^{2}$, \\ Hiroaki Tateno ${ }^{2}$, Naoki Matsumoto ${ }^{1}$, Jun Hirabayashi ${ }^{2}$ and Kazuo Yamamoto ${ }^{1, *}$
}

1 Department of Integrated Biosciences, Graduate School of Frontier Sciences, the University of Tokyo, Chiba 277-8562, Japan; E-Mails: keisuke.soga@gmail.com (K.S.); 137303@ib.k.u-tokyo.ac.jp (H.A.); qinshengying@gmail.com (S.-Y.Q.); kyoutou.takuya@sysmex.co.jp (T.K.); nmatsu@k.u-tokyo.ac.jp (N.M.)

2 Research Center for Stem Cell Engineering, National Institute of Advanced Industrial Science and Technology (AIST), Ibaraki 305-8568, Japan; E-Mails: keiko-hiemori@aist.go.jp (K.H.); h-tateno@aist.go.jp (H.T.); jun-hirabayashi@aist.go.jp (J.H.)

* Author to whom correspondence should be addressed; E-Mail: yamamoto@k.u-tokyo.ac.jp; Tel.: +81-4-7136-3614; Fax: +81-4-7136-3619.

Academic Editor: Hans Vliegenthart

Received: 17 May 2015 / Accepted: 18 June 2015 / Published: 20 July 2015

\begin{abstract}
Leguminous lectins have a conserved carbohydrate recognition site comprising four loops (A-D). Here, we randomly mutated the sequence and length of loops $\mathrm{C}$ and D of peanut agglutinin (PNA) and expressed the proteins on the surface of mouse green fluorescent protein (GFP)-reporter cells. Flow cytometry, limiting dilution, and cDNA cloning were used to screen for several mutated PNAs with distinct properties. The mutated PNA clones obtained using NeuAc $\alpha 2-6(\mathrm{Gal} \beta 1-3)$ GalNAc as a ligand showed preference for NeuAc $\alpha 2-6(G a 1 \beta 1-3)$ GalNAc rather than non-sialylated Gal $\beta 1-3$ GlcNAc, whereas wild-type PNA binds to Gal $\beta 1-3$ GlcNAc but not sialylated Gal $\beta 1-3$ GalNAc. Sequence analyses revealed that for all of the glycan-reactive mutated PNA clones, (i) loop $\mathrm{C}$ was eight amino acids in length, (ii) loop D was identical to that of wild-type PNA, (iii) residue 127 was asparagine, (iv) residue 125 was tryptophan, and (v) residue 130 was hydrophobic tyrosine, phenylalanine, or histidine. The sugar-binding ability of wild-type PNA was increased nine-fold when Tyr125 was mutated to tryptophan, and that of mutated clone $\mathrm{C}$ was increased more than 30-fold after His 130 was changed to tyrosine. These results provide an insight into the relationship between the amino acid sequences of the carbohydrate recognition site and sugar-binding abilities of leguminous lectins.
\end{abstract}


Keywords: leguminous lectin; cell surface display; carbohydrate-binding specificity; molecular engineering; scaffold

\section{Introduction}

Numerous types of glycans are displayed on the surface of mammalian cells and glycans play various important roles in the biological functions of the cell. Profiling of glycan structures, especially on the cell surface, has been performed via either mass spectrometric analyses of released oligosaccharides [1] or lectin microarray analyses of the cell itself [2-5]. Although both methods are highly sensitive and reproducible, mass spectrometric analyses are associated with difficulties in quantitative determinations and specifying anomer structures, whereas lectin microarrays are unable to accommodate some glycan structures. A number of plant lectins, especially leguminous lectins, were studied extensively some decades ago. Leguminous lectins, which form the largest family of lectin proteins, consist of four subunits; each subunit has a carbohydrate recognition site that comprises four loops (A,B,C and D), and calcium and manganese ions are necessary for their sugar-binding activities [6]. Although the amino acid sequences and tertiary structures of various leguminous lectins are similar, they show a variety of sugar-binding specificities. Recognition of complex glycan structures by the sugar-binding site promotes the interaction of lectins with the elongated sugar structure via hydrogen bonds and van der Waals forces. The binding specificity of leguminous lectins is determined by residues located both within and close to the core region of the sugar-binding site. In previous studies, we identified the sugar-binding peptides of several leguminous lectins by affinity chromatography analyses of trypsin or lysylendopeptidase digests on haptenic sugar-immobilized columns [7-9]. Notably, all of these sugar-binding peptides were derived from loop $\mathrm{C}$ of the sugar-binding site, and the replacement of loop $\mathrm{C}$ of the galactose-binding Bauhinia purpurea lectin with that from the mannose-binding Lens culinaris lectin altered the binding specificity from galactose to mannose [10]. $\mathrm{X}$-ray crystallographic analyses of several leguminous lectins in complex with sugar ligands indicated that the long loop $\mathrm{C}$ region is largely involved in both the interaction of a leguminous lectin with its glycan ligand and the determination of sugar-binding specificity.

Lectin engineering technology has recently advanced using site-directed mutagenesis, site-directed saturation mutagenesis, random mutagenesis, and DNA shuffling [11]. The engineered lectins having novel specificity could be useful probes since cell surface glycans on tumor cells are structurally changed in comparison to those of normal cells, and specific probes for such tumor-specific glycans could be anti-cancer drugs $[12,13]$.

Here, we established a method for the efficient expression of leguminous lectin subunits on the surface of mammalian cells without the loss of sugar-binding ability. To evaluate the amino acid sequence, especially in its sugar-binding loops and the sugar-binding specificity of lectins, we introduced random mutations in sugar-binding loops of peanut agglutinin (PNA), expressed on the surface of mammalian cells, and successfully screened for mutated PNAs with novel sugar-binding specificities. The data demonstrated that sugar-binding loop $\mathrm{C}$ was largely involved in the sugar-binding specificity of the lectin and critical amino acid residues associated with sugar-binding activity and specificity were clarified. 


\section{Results}

\subsection{Construction of Mutated PNA Library Plasmids}

The carbohydrate recognition sites of various leguminous lectins, which consist of four peptide loops named A,B,C and D [14], share structural similarities. Loop C is the important contributor to the sugar-binding specificity $[10,15]$, and it has been suggested that the length of loop D also contributes to this feature [16,17] (Figure 1D). Here, we attempted to alter the sugar-binding specificity of PNA by randomly mutating and extending the regions of the PNA cDNA encoding loop C and/or loop D (Figure 1C). To express PNA on the surface of reporter cells, pMXs vectors

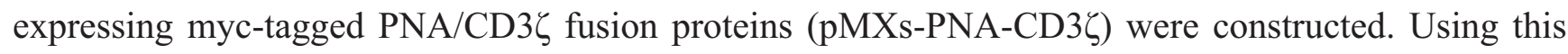
method, the following PNA-mutated library plasmids were prepared: six loop C mutants (C1-C6), four loop D mutants (D1-D4), and one loop C\&D mutant (Figure 1E). In the C1 mutant, with the exception of Asn127, the remaining seven amino acid residues in loop $\mathrm{C}$ were substituted with random amino acids. The $\mathrm{C} 2$ mutant was similar to $\mathrm{C} 1$, with the exception that Asn 127 was also substituted with Asp, Glu, or Gln. The C3, C4, C5, and C6 mutants were similar to C2 but contained an extension of one, two, three, and four amino acids, respectively. In the D1-D4 mutants, six of the seven amino acids in loop D were randomly mutated by polymerase chain reaction (PCR) (Figure 1E). Moreover, the D2 and D3 mutants contained an extension of one and two residues, respectively. The C\&D mutant library was constructed by ligation of the loop $\mathrm{C}$ cDNAs from the mixed loop C libraries (C1-6) into the mixed loop D library plasmids (D1-4). All of the mutated PNA cDNA libraries were inserted into the pMXs retroviral expression vector (Figure 1A). The diversity (independent clone numbers) of each library is shown in Table 1.

Table 1. Diversity of each PNA library.

\begin{tabular}{cc}
\hline Library Name & Colony-Forming Unit \\
\hline C1 & $4.0 \times 10^{6}$ \\
C2 & $3.0 \times 10^{6}$ \\
C3 & $1.8 \times 10^{6}$ \\
C4 & $1.6 \times 10^{6}$ \\
C5 & $1.5 \times 10^{6}$ \\
C6 & $2.0 \times 10^{6}$ \\
D1 & $1.4 \times 10^{5}$ \\
D2 & $1.1 \times 10^{5}$ \\
D3 & $1.0 \times 10^{5}$ \\
D4 & $3.3 \times 10^{5}$ \\
C\&D & $5.0 \times 10^{6}$ \\
Total & $1.96 \times 10^{7}$ \\
\hline
\end{tabular}



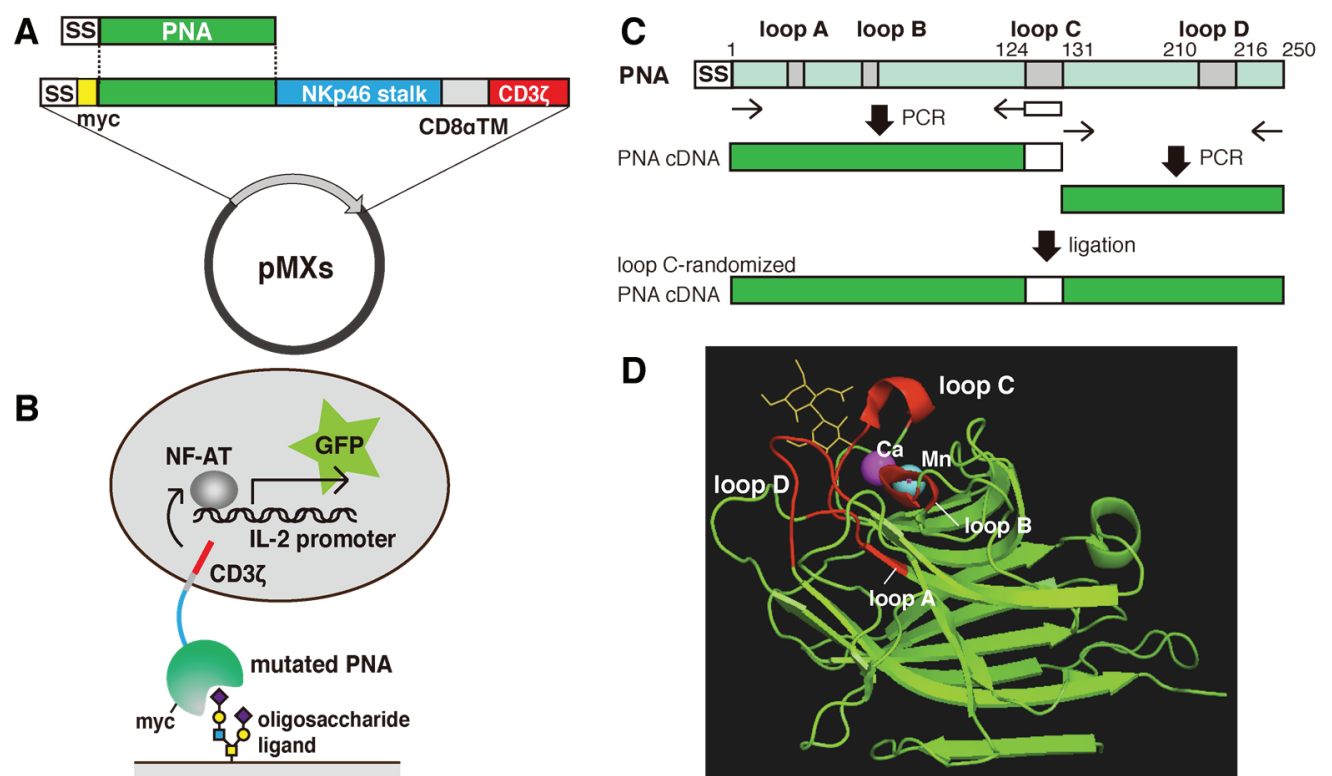

E
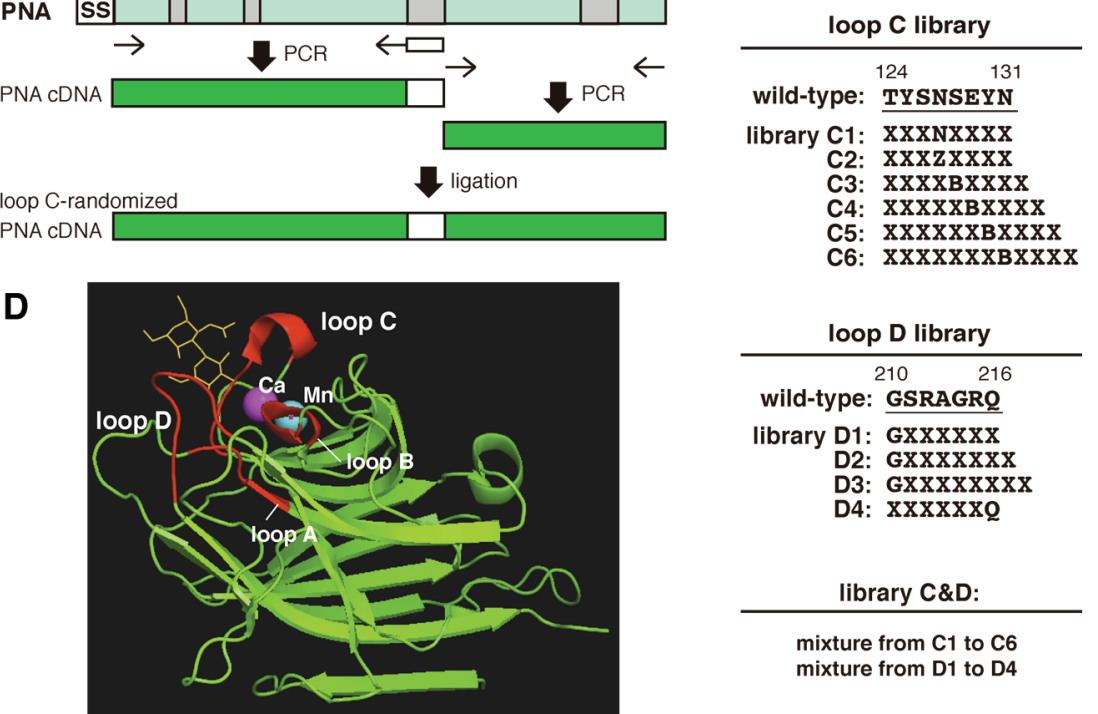

Figure 1. Overview of the methods used to prepare and analyze the mutated PNA libraries. (A) A schematic illustration of the pMXs vector used to express myc-tagged PNA fused to the natural killer cell p46-related protein stalk domain, CD8 $\alpha$ transmembrane domain, and CD3 $\zeta$. SS, CD8 $\beta$ signal sequence; (B) A schematic illustration of the cell surface display method and green fluorescent protein (GFP)-reporter assay used to characterize the mutated PNA proteins; (C) A schematic illustration of the PCR-based method used to construct PNA libraries containing mutations in loop $\mathrm{C}$ of carbohydrate recognition site using degenerate oligonucleotides (white box); (D) Three-dimensional structure of PNA co-crystallized with $\mathrm{N}$-acetyllactosamine (yellow) (1ciw). Carbohydrate recognition site consists of four loops (red) and calcium and manganese ions stabilize loop C for enhancing the interaction between the loop and a sugar ligand; (E) The sequences that were randomly mutated (X) in the loop C, loop D, and loop C\&D PNA libraries (where B = Asp or Asn, and $\mathrm{Z}=$ Glu or Gln).

\subsection{Generation of $2 B 4$ Reporter Cells Displaying Mutated PNAs on the Cell Surface}

The plasmids encoding the mutated PNA libraries were expanded in Escherichia coli and used to screen for novel lectins with distinct characteristics, including sugar-binding specificity. The pMXs retroviral expression vector was used to express mutated PNAs on the surface of mammalian cells; the use of this vector enabled efficient gene transfer and the stable expression of only one or a few kinds of cDNA per cell. The pMXs constructs were introduced into Plat-E cells to obtain retroviral particles containing mutated PNA cDNA. The retroviral particles were then transformed into $2 \mathrm{~B} 4$ cells having a GFP transgene under the control of NF-AT. In transformed 2B4 cells expressing mutated myc-tagged PNA/CD3 $\zeta$ fusion proteins on the cell surface, binding of PNA to an oligosaccharide ligand was transduced into intracellular GFP expression (Figure 1B). As controls, cells expressing

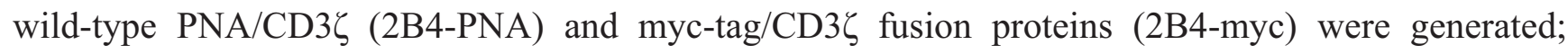
culture of both of these kind of cells in wells coated with anti-myc antibody for $12 \mathrm{~h}$ induced GFP expression (Figure 2A). Culture of 2B4-PNA cells in Galß1-3GalNAc-PAA-coated wells, but not Gal 1 1-3GalNAc-PAA-, Galß1-3GlcNAc-PAA-, or Galß1-4GlcNAc-PAA-coated wells, induced GFP 
expression (Figure 2B). Because Gal $\beta 1-3$ GalNAc is a well-known ligand of PNA $[18,19]$, these results indicate that exogenous PNA displayed on the surface of 2B4 cells was capable of transducing a signal into the cells via cross-linking induced by an immobilized sugar ligand. These data also demonstrate that the interaction between immobilized sugars and lectins displayed on 2B4 cell surfaces could be detected based on the intracellular GFP expression level.
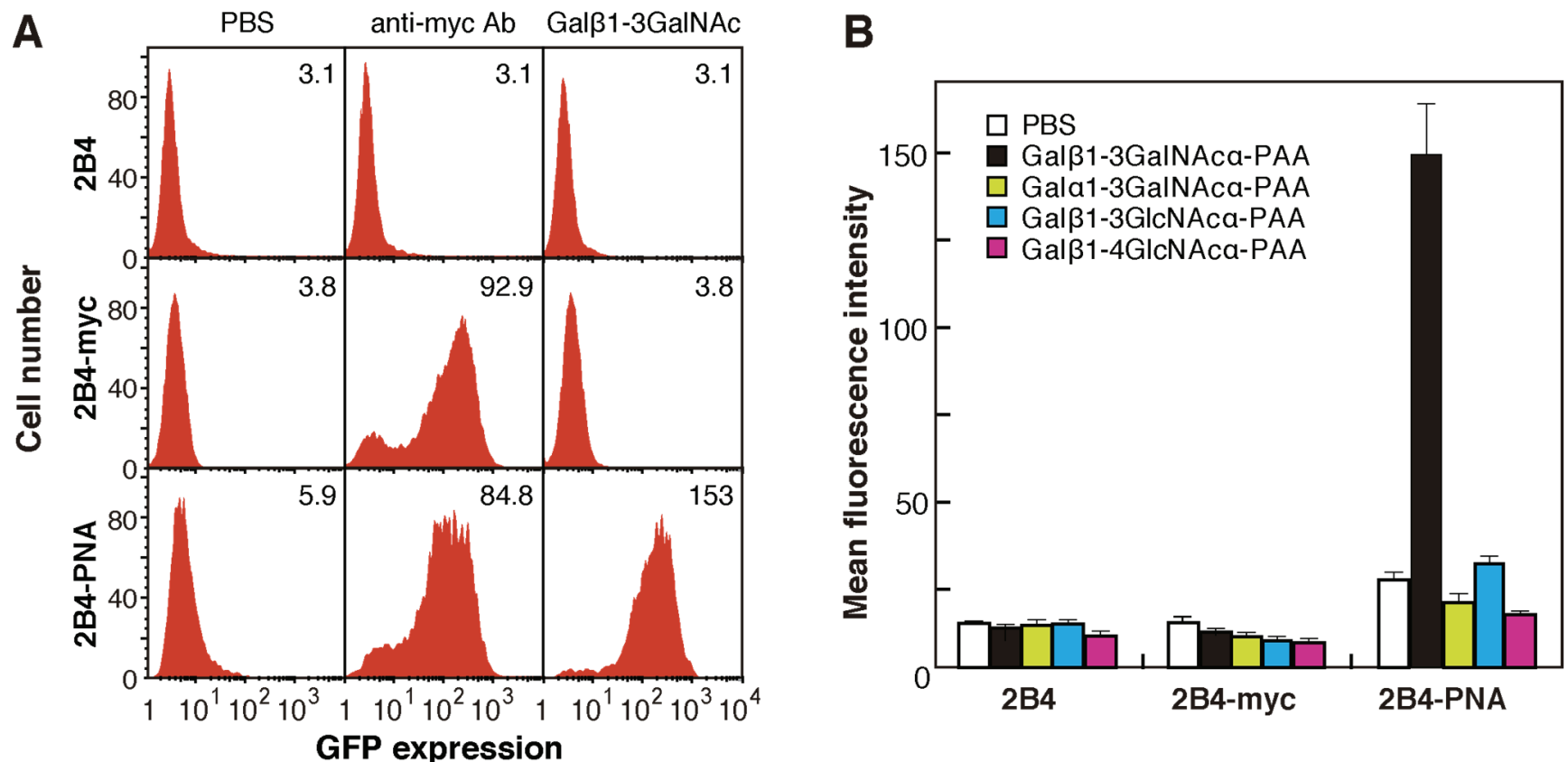

Figure 2. Reporter assays of PNA-expressing 2B4 cells. (A) Fluorescence-activated cell sorting (FACS) analyses of GFP expression in myc-tagged PNA-expressing (2B4-PNA), myc-tag-expressing (2B4-myc), and untransfected 2B4 cells grown on wells coated with anti-myc antibody (middle panels), Gal $\beta 1-3$ GalNAc-PAA (right panels), or PBS as a control (left panels). The numbers in each panel indicate the mean fluorescence intensity; (B) Reporter assay of GFP expression in 2B4-PNA cells grown on wells coated with several disaccharide-PAAs. The data are represented as the mean $\pm \mathrm{SD}$ of $\mathrm{n}=3$ independent experiments.

\subsection{Screening for Mutated Lectins with Novel Sugar-Binding Specificities}

Plasmids containing the mutated PNA libraries (C1-C6, D1-D4, and C\&D) were expressed in 2B4 cells, which were cultured in wells coated with sugar-PAA derivatives for $12 \mathrm{~h}$. Initially, NeuAc $\alpha 2-6(G a 1 \beta 1-3)$ GalNAc $\alpha-P A A$ and NeuAc $\alpha 2-3$ Gal $\beta 1-3 G a l N A c \alpha-P A A$ were used as ligands. Cell fractions expressing large amounts of GFP were collected by cell sorting (approximately 3\% of the cell population in the first round), and the sorting process was repeated two-to-four times using each GFP-positive cell fraction. Compared with those cultured in uncoated wells, GFP-positive cells cultured in NeuAc $\alpha 2-6(G a 1 \beta 1-3)$ GalNAc $\alpha$-PAA-coated wells were efficiently enriched after two rounds of sorting (Figure $3 \mathrm{~A}$ and Figure 4 white squares). By contrast, after growth in NeuAc $\alpha 2-3$ Gal $\beta 1$-3GalNAc $\alpha$-PAA-coated wells, GFP-positive cells were not effectively enriched even after three rounds of sorting (Figure 4 black squares). The same experiments were performed using 12 other sugar-PAAs as ligands, including terminally galactosylated, fucosylated, $N$-acetylglucosaminylated, 
and $\mathrm{N}$-acetylgalactosaminylated oligosaccharides. Moderate enrichment of GFP-positive cells was achieved when Gal $\beta 1-3$ GlcNAc $\beta$-PAA, Gal $\alpha 1-3$ Gal $\beta$-PAA, Gal $\alpha 1-3$ GalNAc $\alpha-P A A$, and GlcNAc $\beta 1$-3GalNAc $\alpha$-PAA were used as ligands (Figure 4). By contrast, GFP-positive cells were not enriched after three rounds of screening using Fuc $\alpha$-PAA, Fuc $\alpha 1-3$ GlcNAc $\beta$-PAA, Fuc $\alpha 1-4 G l c N A c \beta-P A A$, Fuc $\alpha 1-3(G a 1 \beta 1-4) G l c N A c \beta-P A A$, Man $\alpha-P A A$, GlcNAc $\beta-P A A$, GalNAc $\alpha-P A A$, or GalNAc $\alpha 1-3 \mathrm{Gal} \beta$-PAA as ligands (Figure 4B). These results suggest that a scaffold of $\beta$ Gal-binding PNA may be suitable for the recognition of terminal $\beta$-galactose residues.
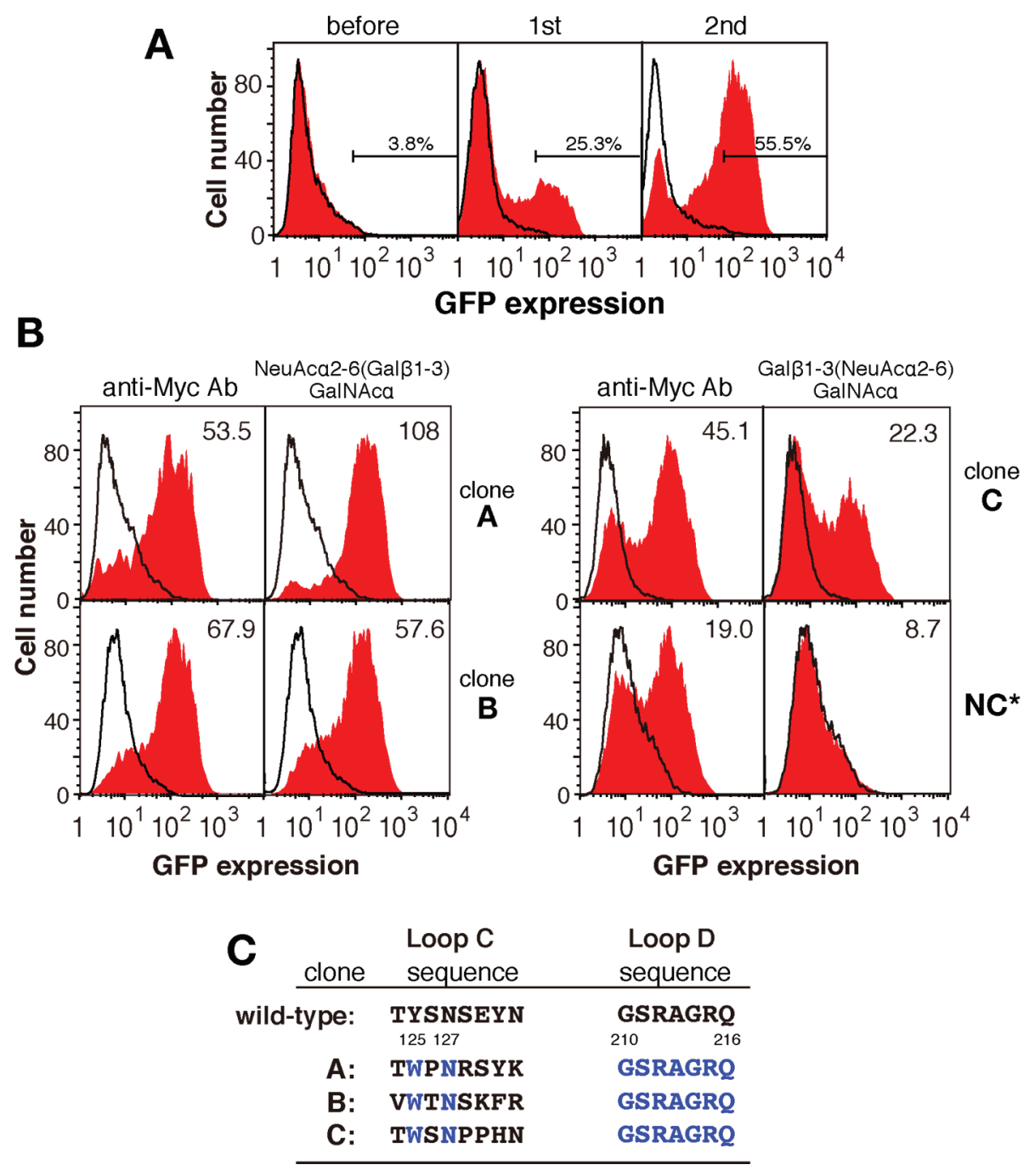

Figure 3. Enrichment of cells expressing mutated PNA. (A) Flow cytometric analyses of cells expressing mutated PNA before and after one or two rounds of selection. The red histogram and solid line indicate GFP expression in the presence or absence of NeuAc $\alpha 2-6($ Gal $\beta 1-3)$ GalNAc-PAA, respectively; (B) Flow cytometric analyses of three mutated PNA clones (A to C) obtained using an anti-myc antibody (left panels) or

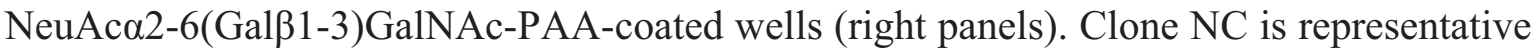
of a negative clone. The red histogram and black line indicate GFP expression in the presence or absence of the ligand, respectively. The numbers in each panel indicate the mean fluorescence intensity; (C) The amino acid sequences of loops $\mathrm{C}$ and $\mathrm{D}$ of mutated PNA clones A-C (deduced from the nucleotide sequences). Blue letters indicate conserved amino acid residues. 


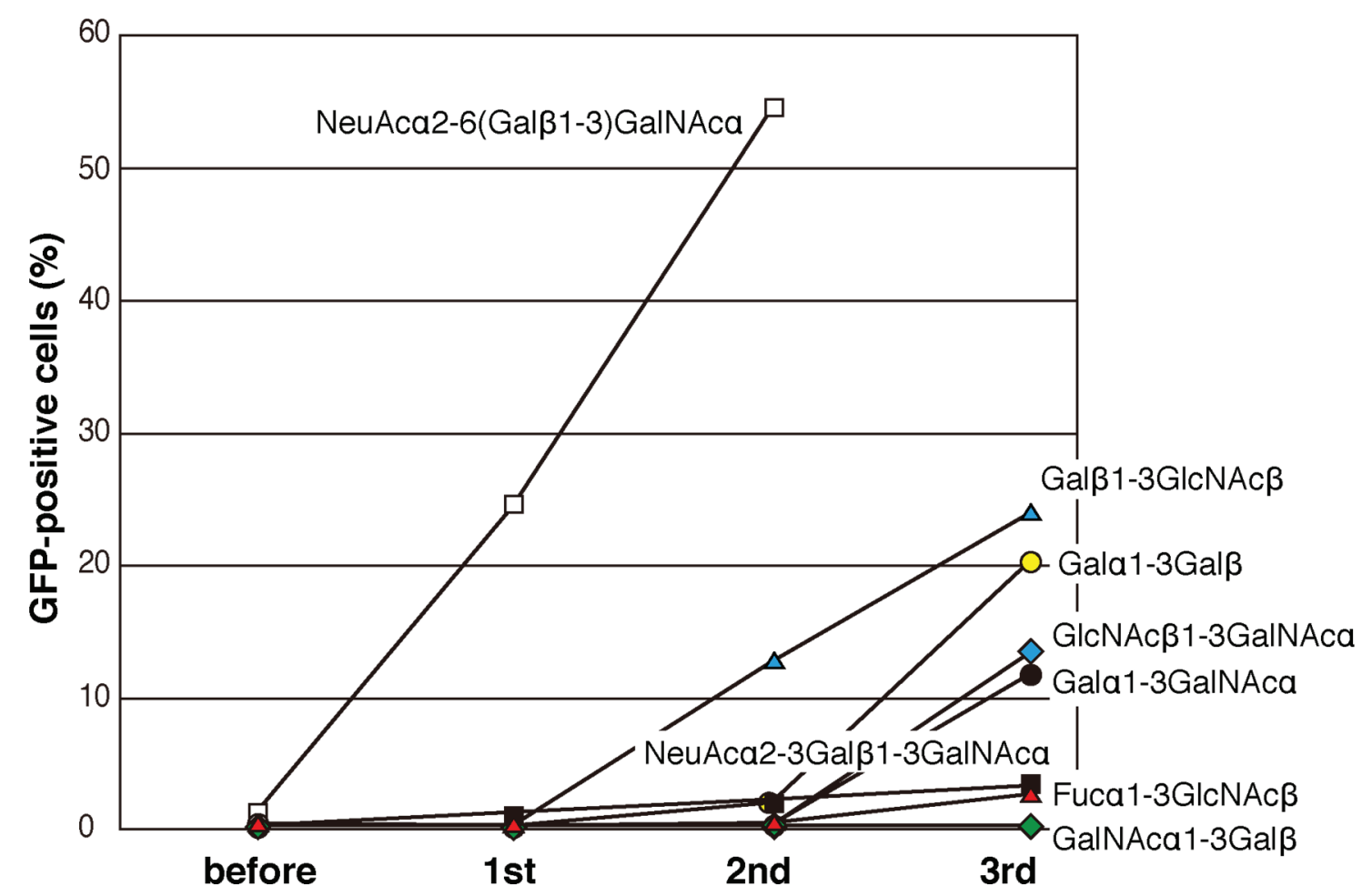

Figure 4. The efficiency of enrichment of GFP-positive 2B4 cells expressing mutated PNA using flow cytometry. GFP-positive cells were defined as cells that showed GFP expression higher than approximately $3 \%$ of the mutated PNA-expressing 2B4 cells before selection. The enrichment of GFP-positive mutated PNA-expressing 2B4 cells in wells coated with Man $\alpha$-PAA, GlcNAc $\beta$-PAA, Fuc $\alpha$-PAA, Fuc $\alpha 1-4$ GlcNAc $\beta-P A A$, and Fuc $\alpha 1-3($ Gal $\beta 1-4)$ GlcNAc $\beta-P A A$ was similar to that in wells coated with GalNAc $\alpha 1-3$ Gal $\beta$-PAA.

Next, GFP-positive cells obtained from two rounds of cultures in NeuAc $\alpha 2-6($ Gal $\beta 1-3)$ GalNAc $\alpha$ PAA-coated wells were cloned by limiting dilution, and 15 independent cell clones expressing mutated PNA proteins were established. Alternatively, GFP-positive cells were collected using a combination of fluorescence microscopy and manipulator as shown in Figure 5. In case of manipulation method, enrichment of GFP-positive cells is not requisite for screening and had an advantage in rapid screening in comparison with the above method using flow cytometry. In this method, we collected more than twenty GFP-positive cells in total and then subjected them to the following genomic DNA extraction.

Genomic DNA was purified from each clone and the mutated PNA cDNAs were amplified by PCR. Overall, two-to-four different mutated PNA cDNAs were amplified from each GFP-positive cell clone, and $15 \mathrm{cDNAs}$ were identified. Each cDNA was then subcloned into the pMXs-PNA-CD3 $\zeta$ vector (replacing the wild-type PNA cDNA) and expressed in 2B4 cells. Each mutated PNA-expressing 2B4 cell was grown in NeuAca2-6(Gal $\beta 1-3)$ GalNAca-PAA-coated wells, and three positive clones (named A to C) were identified by flow cytometry (Figure 3B). The amino acid sequences of loops $\mathrm{C}$ and $\mathrm{D}$ in each mutated PNA protein are shown in Figure $3 \mathrm{C}$. 

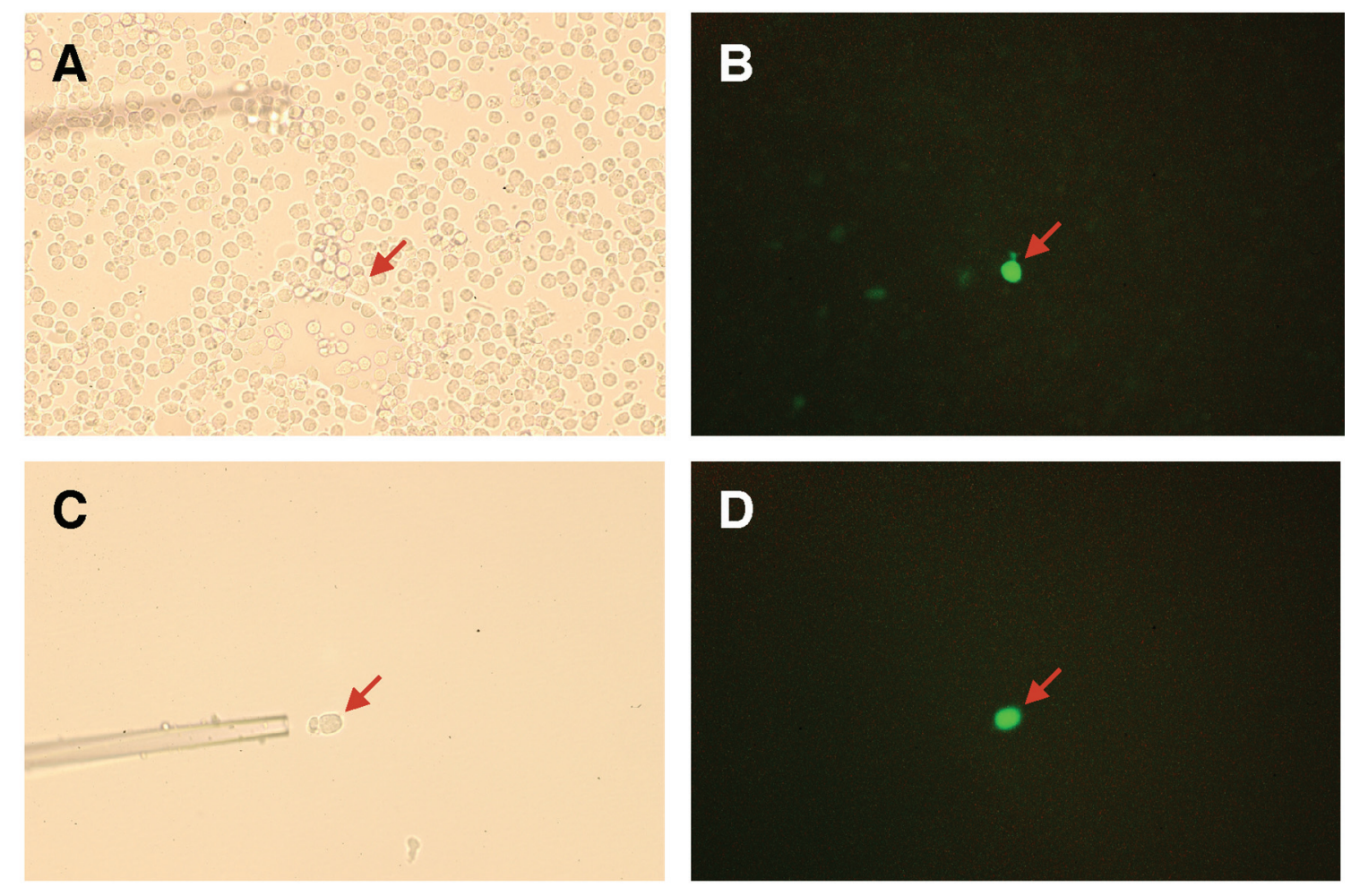

Figure 5. Expression of GFP in mutated PNA-expressing $2 \mathrm{~B} 4$ cells. Mutated PNA library-expressing 2B4 cells were cultured in a NeuAc $\alpha 2-6($ Gal $\beta 1-3)$ GalNAc $\alpha$-PAA-coated well (A,B). A GFP-positive cell was selectively manipulated using a glass capillary $(\mathbf{C}, \mathbf{D})$. GFP-positive cells (red arrow) were visualized using bright-field $(\mathbf{A}, \mathbf{C})$ or fluorescence $(\mathbf{B}, \mathbf{D})$ microscopes.

\subsection{Identification of the Sugar-Binding Specificities of Mutated PNA-IgG Fc Fusion Proteins Using a Glycan Microarray}

To compare their sugar-binding specificities, each cDNA encoding recombinant wild-type and mutated PNA proteins (A to C) were fused to that of $\mathrm{Fc}$ region of human immunoglobulin (Figure 6A) and transformed into HEK293 cells. Each PNA-IgG Fc fusion protein (PNA-Fc) was purified from the culture medium of transformed cells using protein A-Sepharose columns (Figure 6B) and analyzed using a glycan microarray containing a variety of polyacrylamide-derived oligosaccharide polymers and glycoproteins (Figure A1). PNA is used widely as a Galß1-3GalNAc (T antigen)-specific probe [20,21] because its ability to bind to this oligosaccharide is completely abrogated by sialylation of galactose and/or $N$-acetylgalactosamine [22,23]. Wild-type PNA-Fc bound to galactosylated glycans, namely, Gal $\beta 1-3$ GalNAc $\alpha-$, Gal $\beta 1-3($ GlcNAc $\beta 1-6)$ GalNAc $\alpha-$, Gal $\beta 1-4 G 1 c \beta-$, and Gal $\beta 1-3$ GalNAc $\beta-P A A$ (Core1(T), Core2, Lac, and LeC in Figure 7A, respectively), but not to sialylated glycans. By contrast, the mutated PNA clone A Fc fusion protein $(\mathrm{A}-\mathrm{Fc})$, which was enriched by binding to NeuAc $\alpha 2-6(G a 1 \beta 1-3)$ GalNAc $\alpha$-PAA (SAa2-6Core1, Figure 7), bound preferentially to the sialylated glycans NeuAc $\alpha 2-6(G a 1 \beta 1-3)$ GalNAc $\alpha-P A A$ and bovine submaxillary mucin (BSM, Figure 7), whereas its ability to bind to galactosylated glycans was lower than that of wild-type PNA-Fc (Figure 7B). Bovine submaxillary mucin is rich in sialylated $O$-glycans, NeuAca2-6GalNAc (sialyl Tn (STn), Figure 7A), and NeuAc $\alpha 2-6($ GlcNAc $\beta 1-3)$ GalNAc [24]; because A-Fc showed no affinity for STn and 
non-sialylated GlcNAc $\beta 1-3$ GalNAc (Core3, Figure 7A), there may be the possibility that A-Fc can also bind to NeuAc $\alpha 2-6(G l c N A c \beta 1-3)$ GalNAc. Furthermore, like wild-type PNA-Fc, A-Fc was also unable to bind to similar GalNAc- and Fuc-terminated sugar chains (other glycans, Figure 7B). Overall, these observations indicate that $\mathrm{A}-\mathrm{Fc}$ acquired the ability to bind to sialylated NeuAc $\alpha 2-6($ Gal $\beta 1-3)$ GalNAc, but its affinity for desialylated ligands was attenuated compared to that of wild-type PNA (Figure 7C). To our knowledge, this study is the first report of a leguminous lectin that could bind stronger to sialylated NeuAc $\alpha 2-6($ Gal $\beta 1-3)$ GalNAc compared to asialo-Gal-GalNAc.

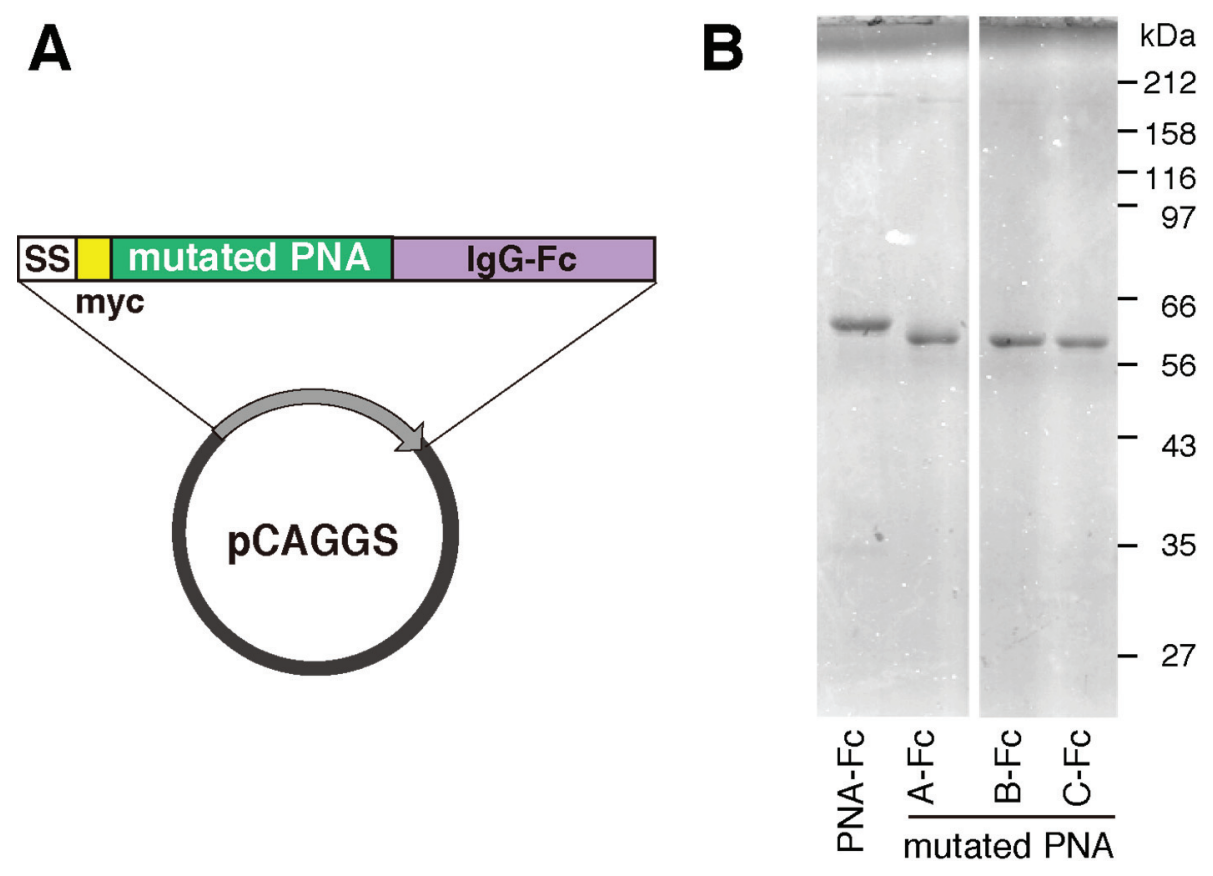

Figure 6. Plasmid construction and sodium dodecyl sulfate-polyacrylamide gel electrophoresis (SDS-PAGE) analyses of mutated PNA-Fc fusion protein. (A) The pCAGGS vector was used to express myc-tagged mutated PNA fused to Fc domain of human IgG; (B) SDS-PAGE analyses of purified wild-type and mutated (A-C) PNA-Fc proteins under reducing conditions.

Fc fusion proteins of the two other mutated PNA clones (B-Fc and C-Fc) were expressed, purified (Figure 7B), and subjected to a glycan microarray analysis as described above. B-Fc showed an enhanced affinity for sialylated glycans and its binding profile was similar to that of A-Fc. C-Fc bound to asialo-glycophorin A, which has $15 O$-glycans of the structure Gal $31-3$ GalNAc (Sigma-Aldrich, St. Louis, MO, USA, partially sialylated). C-Fc also showed a little affinity for other glycans or glycoproteins including sialylated NeuAc $22-6(\mathrm{Gal} \beta 1-3)$ GalNAc (Figure A2), but its affinity for desialylated ligands was relatively attenuated compared with that of PNA-Fc (Figure 7C). Like PNA-Fc, mutated PNA-Fc proteins also showed high affinity for asialo-glycophorin A and Galß1-3GalNAc (Core1(T), Figure 7A), suggesting that mutated clones with a PNA-like scaffold may share some common characteristics. Attempts to evaluate the sugar-binding specificities more precisely and determine the dissociation constant $\left(K_{\mathrm{d}}\right)$ values of the mutated PNA-IgG Fc fusion proteins using frontal affinity chromatography and surface plasmon resonance (using BIAcore technology) were unsuccessful due to their weak binding to ligands. 

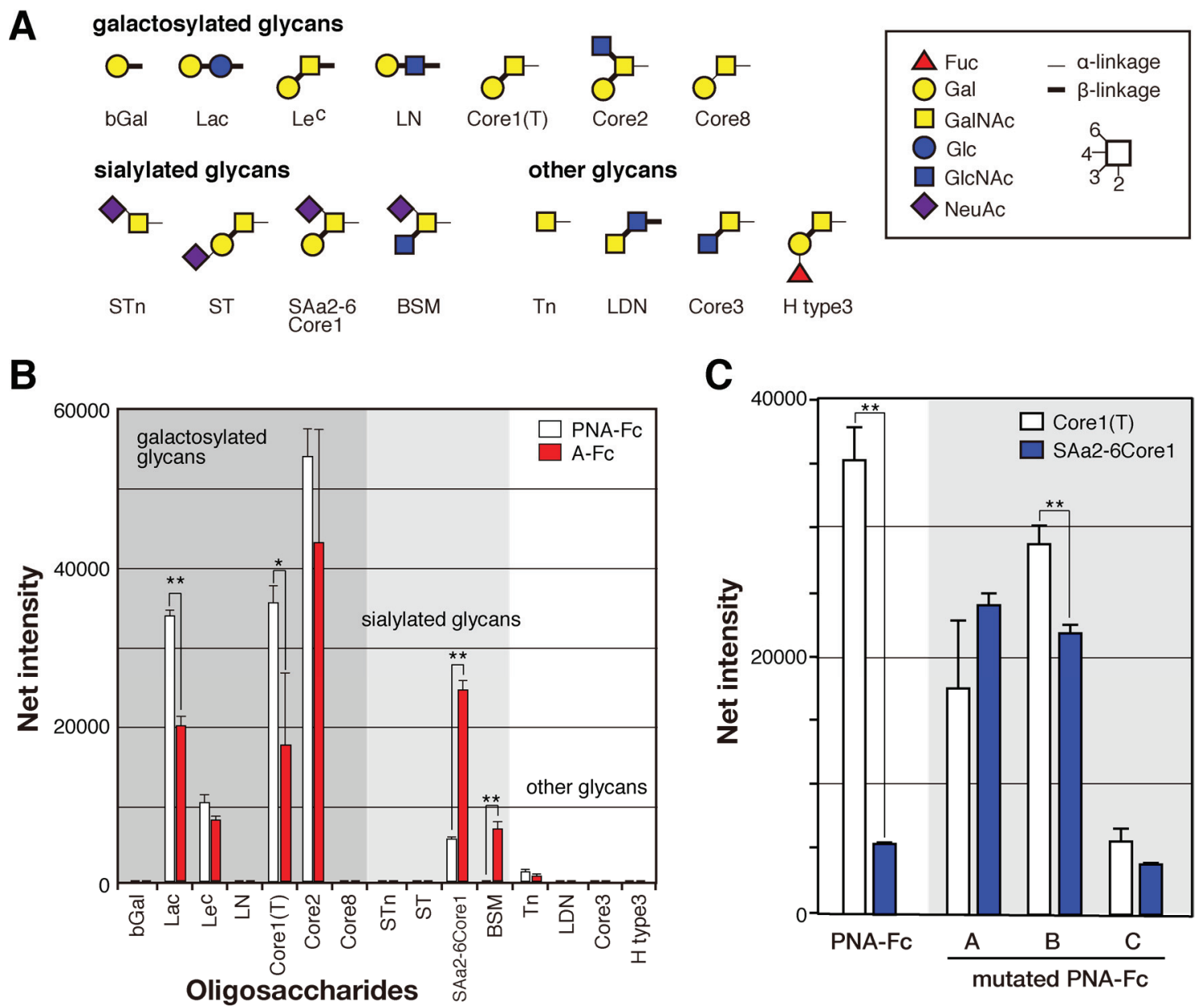

Figure 7. Binding of wild-type and mutated (A-C) PNA-Fc proteins to immobilized multivalent oligosaccharides and glycoproteins. (A) The carbohydrate structures of the polyacrylamide-based oligosaccharides and glycoproteins used for the glycan microarray analysis. All of the oligosaccharides and glycoproteins used in this experiment (98 in total) are shown in Figure A1. Symbols corresponding to each monosaccharide are shown in the inset panel. The thin and thick lines represent $\alpha$ - and $\beta$-linkages, respectively. The glycosidic linkage positions are shown by the numbers on the right side of the panel; (B) Glycan microarray analyses of the binding of wild-type PNA-Fc and A-Fc to the ligands shown in (A), as determined using an evanescent field-activated fluorescence scanner. The data are represented as the mean $\pm \mathrm{SD}$ of $\mathrm{n}=3$ independent spots. $* * p<0.01 ; * p<0.05$ (Student's $t$-test); (C) The binding of wild-type and mutated (A-C) PNA-Fc proteins to

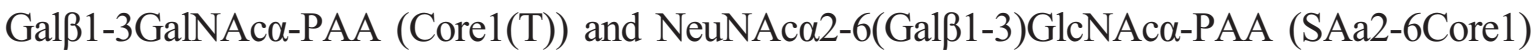
as determined by glycan microarray analyses. The data are represented as the mean $\pm \mathrm{SD}$ of $n=3$ independent spots. The binding of wild-type and mutated PNAs against other glycans is shown in Figure A2. ${ }^{* *} p<0.01$ (Student's $t$-test).

\subsection{The Amino Acid Sequences of Loops $C$ and D from the Mutated PNA Proteins Isolated Using NeuAca2-6(Galß1-3)GalNAc}

As mentioned above, in the screening performed using NeuAca2-6(Gal $\beta 1-3)$ GalNAc as a probe, three different mutated PNA clones were generated. Initially, the randomized loop C and loop D lectin 
libraries were screened for mutant PNA proteins that had novel sugar-binding specificities and differed from wild-type PNA in both amino acid sequence and length. However, all of the mutated PNA clones obtained contained eight amino acids in loop C. Although the length of loop C differs among galactose-, mannose-, $N$-acetylglucosamine-, and $N$-acetylgalactosamine-binding leguminous lectins [17], the insertion of additional amino acid(s) into this region may disrupt the ability of ligands to access the carbohydrate recognition site. All of the mutated PNA clones enriched from the randomized loop $\mathrm{C}$ and loop D lectin libraries that retained sugar-binding activity contained mutations in loop C only, suggesting that the substitution and elongation of loop D abrogates the sugar-binding ability of PNA.

It is well known that an asparagine residue located in the middle of loop $\mathrm{C}$ is strictly conserved in leguminous lectins and the substitution of this residue causes a loss of activity [25-27]. Conservation of the asparagine residue in loop $\mathrm{C}$ is explained by its involvement in coordinate binding to calcium ions and cooperative hydrogen bonding to sugar ligands. To avoid disrupting this characteristic, we replaced the asparagine residue in loop $\mathrm{C}$ with glutamine, glutamic acid, or aspartic acid; however, all of the obtained mutated PNA clones retained asparagine at residue 127 in loop C (Figure 3C). This result demonstrates that conserved asparagine 127 in PNA is essential for its sugar-binding ability.

Residue 125 of the wild-type and mutated PNA proteins was tyrosine or tryptophan (Figure 3C). A previous X-ray crystallographic analysis of PNA complexed with its sugar ligand showed that Tyr125 of PNA interacts with sugar rings via van der Waals contacts. Similarly, tryptophan also seems to bind to sugar rings via van der Waals contacts. When Tyr125 of wild-type PNA was changed to tryptophan, the

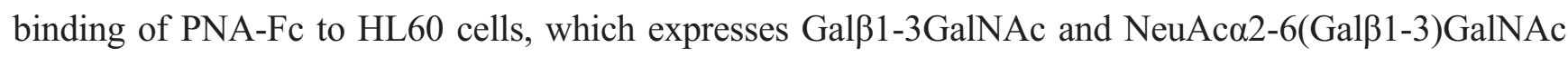
as major $O$-glycans on their cell surfaces [28], was increased by more than nine-fold (Figure 8A). Similarly, when Trp125 of mutated PNA clone A was replaced with tyrosine, its ability to bind to HL60 cells was decreased by approximately 20-fold (Figure 8A). Therefore, the sugar-binding ability of both PNA and mutated PNA was in the order of Trp125 > Tyr125.

Residue 130 of the wild-type and mutated PNA proteins was tyrosine, phenylalanine, or histidine (Figure 3C). An X-ray crystallographic analysis revealed that Tyr130 in wild-type PNA forms hydrogen bonds with structural water molecules [29]. When Tyr130 was changed to histidine, the binding of PNA-Fc to HL60 cells was decreased by 90\%, whereas replacement of His 130 in mutated PNA clone $\mathrm{C}$ with tyrosine increased its ability to bind to HL60 cells by more than 30-fold (Figure 8B).

In mutated PNA clone A, which had a stronger sugar-binding ability than the other mutated clones obtained and was identified by screening for binding to sialylated NeuAca2-6(Galß1-3)GalNAc, the asparagine residue at position 131 of wild-type PNA was substituted to lysine. Positively charged amino acids in loop $\mathrm{C}$ may contribute to binding to sialic acid residues of the glycan ligand; therefore, we determined the contribution of Lys131 of mutated PNA clone A to ligand binding by replacing it with asparagine, which is the corresponding residue in wild-type PNA. As expected, the binding of A-Fc to HL60 cells, which express high levels of $\alpha$ GalNAc: $\alpha 2,6$-sialyltransferase [28], was decreased by approximately 70\% when Lys131 was replaced with asparagine; however, the substitution of Asn131 in wild-type PNA with lysine did not increase its binding ability to the cell (Figure 8C). Though the substitution of Asn131 to Lys of wild-type PNA might change the target glycan from asialo-Gal $\beta 1-3$ GalNAc to the sialylated one on HL60 cell, these results suggest that Lys131 may contribute to the binding of PNA to acidic glycans, but other amino acids in loop C may help to promote the interaction of Lys131 with sialic acid residues. 

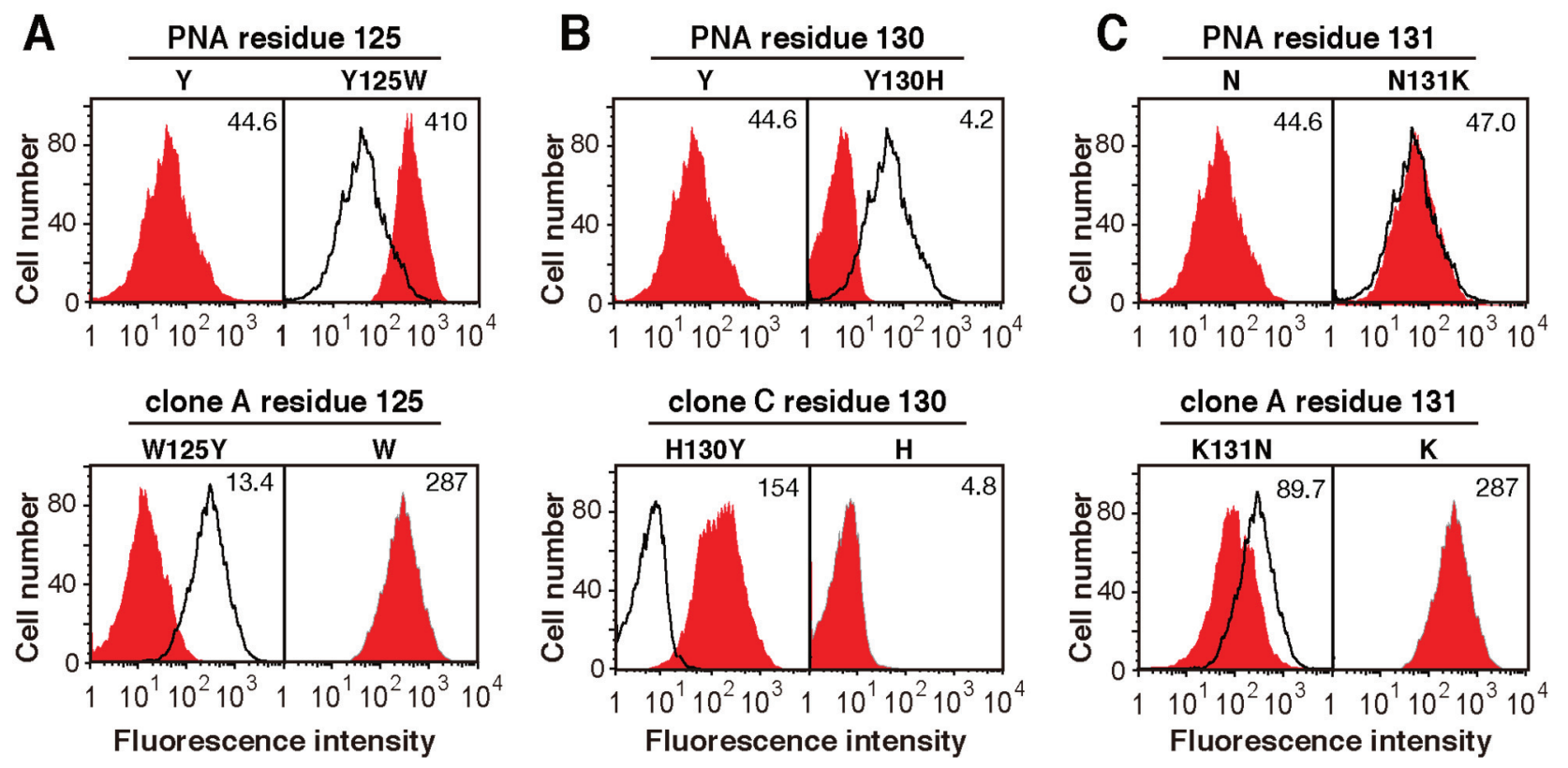

Figure 8. Flow cytometric analyses of the effects of single amino acid substitutions in loop C on the ability of wild-type and mutated PNAs to bind to HL60 cells. (A) The ability of wild-type PNA-Fc to bind to HL60 cells before (Y) and after Tyr125 was mutated to tryptophan (Y125W). Similarly, the binding of A-Fc to HL60 cells was measured before (W) and after Trp125 was replaced with tyrosine (W125Y); (B) The ability of wild-type PNA-Fc to bind to HL60 cells before (Y) and after Tyr130 was mutated to histidine (Y130H). Similarly, the binding of C-Fc to HL60 cells was measured before (H) and after His130 was replaced with tyrosine (H130Y); (C) The ability of wild-type PNA-Fc to bind to HL60 cells before (N) and after Asn131 was mutated to lysine (N131K). Similarly, the binding of A-Fc to HL60 cell was measured before (K) and after Lys 131 was replaced with asparagine $(\mathrm{K} 131 \mathrm{~N})$. The numbers in each panel indicate the mean fluorescence intensity. In the panels showing results for the PNA proteins in which residue 125, 130, or 131 was substituted, the solid lines and red histograms indicate binding before and after substitution, respectively. Similarly, in the panels showing results for mutated PNA-Fc proteins in which residue 125,130 , or 131 was substituted, the solid lines and red histograms indicate binding before and after substitution, respectively.

\section{Discussion}

Previously, we generated several mutated lectins with altered sugar-binding specificities using phage-display [30] and ribosome-display systems [31,32]. Although phage-display and ribosome-display are convenient screening methods for the selection and evolution of peptides or single-chain antibodies [33-35], they have some disadvantages when used for the selection of mutated lectins. First, high molecular weight proteins are not suitable for expression in these systems because the correct folding of recombinant proteins does not occur efficiently in E. coli cells or in vitro. Furthermore, in the case of phage-display systems, the efficiency of display of objective proteins on phage particles is quite low and the technique is limited to low molecular weight peptides. Second, both phage-display and ribosome-display methods require washing steps to remove unbound materials, which may lead to dissociation of the weak interactions between lectins and glycans $\left(K_{a} \sim 10^{4} \mathrm{M}^{-1}\right)$. 
To overcome the difficulties associated with conventional methods of protein display, we successfully established a mammalian cell surface display (MCSD) method for the screening of mutated lectins having sugar-binding activity. Because mammalian cells have a sophisticated protein quality control system, which ensures that correctly folded proteins are expressed preferentially in the cell, the MCSD method enables the expression of high molecular weight proteins. Another advantage of the MCSD method is that weak sugar-protein interactions can be monitored by the transduced expression of GFP in the cell, and subsequent washing steps to remove unbound ligands do not affect this signal. Furthermore, because multivalency increases the avidity of the interaction, the MCSD method is able to monitor the weak binding of lectins to glycans; in fact, one of the mutated lectins obtained using the MCSD method showed almost undetectable affinity for many glycans or glycoproteins when tested using glycan microarrays (Figure A2, C-Fc). Based on the reasons described above, we propose that the MCSD method is superior to conventional methods in terms of efficiency, sensitivity, and reproducibility, not only for the screening of novel lectins but also for the identification of ligands of lectin-like receptors. A potential drawback of the MCSD system is the possibility of false negative GFP signals caused by the disruption of the binding of displayed lectins to immobilized glycans by endogenous glycans on the mammalian cell surface. To minimize this effect, it was necessary to control the cell culture conditions carefully, particularly the cell density and culture period.

It is well-known that PNA is specific for Galß1-3GalNAc. By introducing amino acid substitutions into the sugar-binding loop $\mathrm{C}$ of PNA, we established novel mutated lectins that bound specifically to NeuAc $\alpha 2-6(\mathrm{Gal} \beta 1-3)$ GalNAc. In a previous study, PNA was used to fractionate mouse or human thymocytes into two populations, namely PNA-agglutinated cells consisting mainly of immature cortical cells, and PNA-unagglutinated mature medullary thymocytes [36]. Leukocytes express leukosialin, a major $O$-glycan-containing sialoglycoprotein, and the structure of $O$-glycans depends on the leukocyte cell lineage and differentiation stage. NeuAc $\alpha 2-6(N e u A c \alpha 2-3$ Gal $\beta 1-3)$ GalNAc is the major constituent of leukosialin-attached $O$-glycan in resting T-lymphocytes, whereas the level of Gal $\beta 1-4 \mathrm{GlcNAc} \beta 1-6(\mathrm{Gal} \beta 1-3)$ GalNAc is increased in activated T-lymphocytes [37]. Maackia amurensis hemagglutinin (MAH) binds specifically to the sialylated $O$-glycan NeuAc $\alpha 2-6(\mathrm{NeuAc} \alpha 2-3 \mathrm{Gal} \beta 1-3)$ GalNAc but not NeuAc $\alpha 2-6(\mathrm{Gal} \beta 1-3)$ GalNAc [38]. Since the $O$-glycan structures on leukocytes are useful markers of immune cell subpopulations along with MAH and wild-type PNA, mutated PNA clones A, B and C could be candidates for convenient cell probes.

The screening of several mutated PNAs with an affinity for NeuAc $\alpha 2-6(\mathrm{Gal} \beta 1-3)$ GalNAc provided new insights into the amino acid residues that are responsible for the sugar-binding activity of leguminous lectins. In addition, mutated PNAs with no affinity for glycans were also obtained during the screening and the amino acid sequences of sugar-binding loops $\mathrm{C}$ and $\mathrm{D}$ of these proteins may also be helpful for understanding the involvement of critical amino acid residues in sugar-binding. First, we found that residue 127 of all of the mutated PNA proteins was asparagine; it is well known that asparagine residues in loop $\mathrm{C}$ are highly conserved across leguminous lectins, with the exception of the sialic acid-binding MAH lectins [17,39,40]. A previous X-ray crystallographic analysis of PNA demonstrated the involvement of asparagine in both coordinate binding to calcium ions and cooperative hydrogen bonding to sugar ligands. Second, residue 125 of wild-type and mutated PNAs was tyrosine or tryptophan. The residue at this position makes contact with a sugar ring via van der 
Waals interaction [29] and the mutation of Tyr125 in wild-type PNA to tryptophan-enhanced binding of the lectin to HL60 cells (Figure 8A). Similarly, the mutation of Trp125 of mutated PNA clone A to tyrosine decreased its ability to bind to HL60 cells (Figure 8A). Understanding the importance of the specific residue at position 125 may be useful for the generation of engineered leguminous lectins with enhanced binding ability. Third, we hypothesized that basic amino acids in loop $\mathrm{C}$ may enhance the binding of PNA to sialic acid-containing glycans. The replacement of Lys 131 of mutated PNA clone A with asparagine, the residue found at this position in wild-type PNA, decreased its ability to bind to mammalian cells; however, the mutation of Asn131 in wild-type PNA to lysine did not affect its binding ability (Figure 8C). In sialic acid-binding Maackia amurensis lectins, a lysine residue in loop B forms hydrogen bonds with the carboxyl group of sialic acid in an unconventional binding mode [41]. Additional studies, such as X-ray crystallographic analyses, will clarify the involvement of these lysine residues in sugar recognition.

The length and composition of loop D of lectins are also thought to be involved in determining the sugar-binding specificity. However, although we prepared PNA proteins containing mutations in loop D, all of the mutated clones that retained sugar-binding ability contained the wild-type loop D sequence. Substitutions of a few amino acids in loop D might cause a conformational change in the sugar-binding site, resulting in a loss of sugar-binding ability.

Although PNA is specific for Galß1-3GalNAc, this study raised the possibility that mutations in PNA produce novel lectins that are capable of recognizing Galß1-3GlcNAc, Gal 1 1-3Gal, GlcNAc $\beta 1$-3GalNAc, and Gal $\alpha 1-3$ GalNAc. Since efficient enrichment of the mutated PNAs was achieved using galactosylated glycans as ligands (Figure 4), it is possible that the scaffold of PNA can be optimized to enable binding of terminal galactose residues. The lengths of loop $\mathrm{C}$ from galactose/ $N$-acetylgalactosamine-binding, mannose/glucose-binding, $N$-acetylglucosamine-binding, and sialic acid-binding leguminous lectins are approximately eight, eight, ten, and ten residues, respectively $[17,40]$. Based on a relationship between the length of loop $\mathrm{C}$ and its monosaccharide-binding specificity, we hypothesized that mutated PNAs specific for mannose, fucose, or $N$-acetylglucosamine could be established by adjusting the length of loop C (Figure 1D). However, the lengths of the loop C regions in the mutated PNA clones obtained using NeuAc $\alpha 2-6($ Gal $\beta 1-3)$ GalNAc were the same as that of wild-type PNA loop C. Furthermore, both the lengths and amino acid sequences of the loop D regions in the mutated PNA clones obtained using NeuAc $\alpha 2-6(\mathrm{Gal} \beta 1-3)$ GalNAc as a ligand were the same as those of the wild-type PNA loop D. Other clones with different loop C and/or loop D lengths were also obtained during the screening; however, these clones did not show any sugar-binding ability in the reporter assay. Alterations in the length of loop $\mathrm{C}$ in the PNA scaffold may cause decreased expression of the protein, resulting in inefficient screening of mutated PNAs.

\section{Experimental Section}

\subsection{Cells and Reagents}

A human T cell hybridoma (2B4) harboring a GFP-reporter gene under the control of the nuclear factor of activated T cells (NF-AT) was kindly provided by Dr. H. Arase (Osaka University, Osaka, Japan) [42]. The retroviral vector, pMXs vector, and Plat-E retrovirus-packaging cells were provided by Dr. T. Kitamura (The Institute of Medical Sciences, The University of Tokyo, Tokyo, Japan) and 
were used for retrovirus transduction throughout this study [43]. The HEK293 cell was obtained from the Cell Resource Center for Biomedical Research (Tohoku University, Miyagi, Japan). The Plat-E cells were maintained in DMEM (Invitrogen, Carlsbad, CA, USA) supplemented with 25 mM HEPES (pH 7.4), $2 \mathrm{mM}$ glutamine, $10 \mu \mathrm{g} / \mathrm{mL}$ blasticidin S (Invitrogen), and $1 \mu \mathrm{g} / \mathrm{ml}$ puromycin (Sigma-Aldrich). The 2B4 and HEK293 cells were cultured in DMEM supplemented with 10\% heat-inactivated FBS, $2 \mathrm{mM}$ glutamine, and $25 \mathrm{mM}$ HEPES (pH 7.4). All cell lines were cultured at $37^{\circ} \mathrm{C}$ under $5 \% \mathrm{CO}_{2}$ conditions.

\subsection{Establishment of PNA and Mutated PNA Library-Expressing Reporter Cells}

Total RNAs were extracted from germinated peanut (Arachis hypogaea) seeds using the RNeasy Mini Kit (Qiagen, Valencia, CA, USA), and cDNAs were prepared by SuperScript III First-Strand Synthesis System (Qiagen). The cDNA encoding PNA was amplified by PCR using a forward primer (5'-CGGAATTCGCCGAAACAGTTTCCTTCC-3') and a reverse primer (5'-CCGCTCGAGTGCACTTGCACTTGCCATATTCAT-3') that contained an internal EcoRI and XhoI site, respectively. The obtained cDNA encoded a natural variant of PNA in which His139, Leu235, and Gly236 were substituted with Tyr, Arg, and Ala, respectively (AB917153) [44]. To express PNA on the surface of the 2B4 reporter cells, pMXs vectors containing cDNAs encoding the CD8 $\beta$ signal sequence, followed by myc-tagged PNA, the natural killer cell p46-related protein stalk domain, the $\mathrm{CD} 8 \alpha$ transmembrane domain, and the mouse CD3 $\zeta$ cytoplasmic domain (pMXs-PNA-CD3 ), were constructed (Figure 1A). A PNA library containing mutations in loop $\mathrm{C}$ of the carbohydrate recognition domain was constructed by amplifying and ligating the $5^{\prime}$ and $3^{\prime}$ halves of the PNA cDNA (Figure 1C). The 5' half was amplified by PCR using the following primers: forward, 5'-GAAGGCCTCCCACTGATCACGTTGGA-3', and reverse, 5'-AACATTCTCGAGTGCACTTGCCATATTCAT-3'. The 3' half was also amplified by PCR and the region corresponding to loop $\mathrm{C}$ was randomized by using the following forward primer and degenerate reverse primers: forward, 5'-CGGAATTCGCCGAAACAGTTTCCTTCC-3'; reverse C1, 5'-ATCMNNM NNMNNMNNGTTMNNMNNMNNATCAAACTCCACTCCAAC-3'; reverse C2, 5'-ATCMNNMNN MNNMNNNTSMNNMNNMNNATCAAACTCCACTCCAAC-3'; reverse C3, 5'-ATCMNNMNNMN NMNNNTBMNNMNNMNNMNNATCAAACTCCACTCCAAC-3'; reverse C4, 5'-ATCMNNMNNM NNMNNNTBMNNMNNMNNMNNMNNATCAAACTCCACTCCAAC-3'; reverse C5, 5'-ATCMNN MNNMNNMNNNTBMNNMNNMNNMNNMNNMNNATCAAACTCCACTCCAAC-3'; or reverse C6, 5'-ATCMNNMNNMNNMNNNTBMNNMNNMNNMNNMNNMNNMNNATCAAACTCCACTCCAAC-3' (where $\mathrm{M}=\mathrm{A}$ or $\mathrm{C}, \mathrm{N}=\mathrm{A}, \mathrm{T}, \mathrm{G}$, or $\mathrm{C}$, and $\mathrm{B}=\mathrm{T}, \mathrm{G}$, or $\mathrm{C}$ ). The amplified DNAs were inserted into

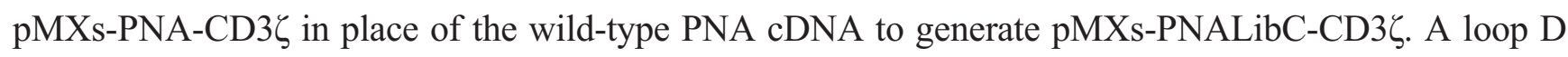
carbohydrate-recognition domain library of PNA was also constructed using a similar strategy to that described above. Briefly, the $5^{\prime}$ half of the PNA cDNA was amplified by PCR using the following primers: forward, 5'-CGGAATTCGCCGAAACAGTTTCCTTCC-3', and reverse, 5'-AAGTTAACCGA ACTTGACCCTCT-3'. The 3' half of the PNA cDNA containing loop D was also amplified by PCR using the following reverse primer and degenerate forward primers: reverse, 5'-CCCTTTTTCTG GAGACTAAAT-3'; forward D1, 5'-TTTCTGCCTCCGGCNNMNNMNNMNNMNNMNNMAT ACATCTCATCCGTTCA-3'; forward D2, 5'-TTTCTGCCTCCGGC NNMNNMNNMNNMNNMN NMNNMATACATCTCATCCGTTCA-3'; forward D3, 5'-TTTCTGCCTCCGGCNNMNNMNNM NNMNNMNNMNNMNNMATACATCTCATCCGTTCA-3'; or forward D4, 5'-TTTCTGCCTC 
CNNMNNMNNMNNMNNMNNMATACATCTCATCCGT TCA-3'. The ${ }^{\prime}$ ' and 3 ' halves were then ligated into pMXs to generate pMXs-PNALibD-CD3 $\zeta$. Finally, a PNA library containing mutations in both loop $\mathrm{C}$ and loop D was constructed. Briefly, the cDNAs containing randomized loop $\mathrm{C}$ were obtained by digestion of the PNA loop C library with PacI and HindIII, and then inserted into pMXs-PNALibD-CD3 $\zeta$ at the same sites to generate pMXs-PNALibCD-CD3 $\zeta$. The constructed plasmids were transformed into E. coli ElectroMAX DH10B cells (Invitrogen) by electroporation ( $1.8 \mathrm{kV}$, $186 \mathrm{ohm}$, and $50 \mu \mathrm{F}$ for $7.8 \mathrm{~ms}$ ). The plasmids (originating from $1.96 \times 10^{7} \mathrm{cfu}$; Table 1) were then purified from the propagated $E$. coli cells. After recovery of retrovirus particles formed by the transfection

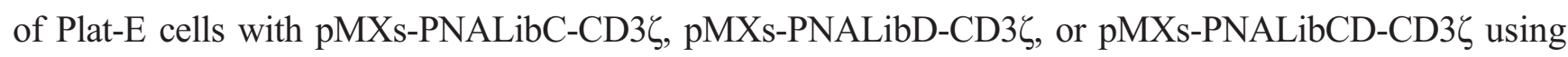
Lipofectamine 2000 reagent (Invitrogen), 2B4 cells $\left(2.5 \times 10^{6}\right)$, which contained a GFP-reporter gene under the control of NF-AT, were infected with the retroviruses to induce the cell surface expression of wild-type or mutated PNA.

\subsection{Screening of Engineered Lectins from Mutated PNA Library-Expressing Cells by a GFP-Reporter Assay}

The 2B4 cells expressing mutated PNA on their cell surface were stained with an anti-myc antibody (9E10; American Type Culture Collection, Manassas, VA, USA) and $R$-phycoerythrin-labeled goat anti-mouse IgG-F(ab')2 (Beckman Coulter, Fullerton, CA, USA), and then enriched using a FACS Vantage SE cell sorter (BD Biosciences, San Jose, CA, USA) based on the expression of the myc-tag. The enriched 2B4 cells expressing mutated PNA were cultured in 6-well ELISA plates (Iwaki, Tokyo, Japan) coated with acrylamide-based multivalent sugar polymers (sugar-PAA) (GlycoTech, Gaitheresburg, MD, USA) for $16 \mathrm{~h}$ at $37^{\circ} \mathrm{C}$. The $2 \mathrm{~B} 4$ cells with higher GFP expression (less than $3 \%$ of the population) were collected using the FACS Vantage SE instrument (BD Biosystems, San Jose, CA, USA) and cultured for the next round of sorting. After enrichment of the GFP-positive cells was repeated two or three times, each cell was cloned by limiting dilution. A reporter assay of each cloned cell grown on various sugar-PAA-coated wells was performed using the FACS Calibur system (BD Biosciences), and the data were analyzed using FlowJo software (TreeStar, San Carlos, CA, USA).

Alternatively, GFP-positive 2B4 cells expressing mutated PNA, which had been cultured in a $9 \mathrm{~mm}$ petridish (BD Falcon, Bedford, MA, USA) coated with acrylamide-based multivalent sugar polymers, were visualized by fluorescence microscopy and approximately twenty GFP-positive cells were collected using the piezo micromanupilator, PMM-150HJ (Prime tech, Ibaraki, Japan).

\subsection{Isolation and Sequencing of Cloned Mutated PNA cDNAs}

Genomic DNA was extracted from the cloned GFP-positive cells using the FlexiGene DNA Kit (Qiagen) according to the manufacturer's protocol. The cDNAs encoding mutated lectins were then amplified by PCR using a forward primer (5'-CGGAATTCGCCGAAACAGTTTCCTTCC-3') containing an EcoRI site and a reverse primer (5'-CCGCTCGAGTGCACTTGCCATATTCAT-3') containing an XhoI site, subcloned into the pBluescript II SK(+) vector, and sequenced using an ABI 3500/3500xL genetic analyzer (Applied Biosystems, Foster City, CA, USA). Each putative lectin cDNA was subcloned into pMXs-CD3 $\zeta$ and expressed in 2B4 cells. Cloned lectin mutants expressed on the cell surface were subjected to GFP-reporter assays in several different sugar-PAA coated wells, as described above. 


\subsection{Preparation of Mutated PNA-IgG Fc Fusion Proteins}

A cloned lectin cDNA fused to the cDNA encoding the Fc segment of human $\mathrm{IgG}_{1}$ (provided by Dr. H. Arase, Osaka University) was inserted into the pCAGGS vector to generate pCAGGS-mPNA-Fc [45]. HEK293 cells were transfected with pCAGGS-mPNA-Fc using Lipofectamine 2000 reagent, and cells stably secreting mutated PNA-Fc proteins were selected by culturing in medium containing $1 \mathrm{mg} / \mathrm{mL}$ G418 (Sigma-Aldrich). After the cloning of G418-resistant cells by limiting dilution, the clone that displayed the highest production of the mutated PNA-Fc fusion protein was chosen and subjected to a large-scale culture. The mutated PNA-Fc fusion protein was purified from conditioned media of the cells by affinity chromatography using a HiTrap rProtein A FF column (GE Healthcare, Piscataway, NJ, USA) and the AKTA Explorer system (GE Healthcare). The purity was confirmed by SDS-PAGE under reducing conditions. To introduce a single mutation into the cDNAs encoding PNA-Fc and mutated PNA-Fc clones A and D, the KOD-Plus-Mutagenesis Kit (Toyobo, Osaka, Japan) was used according to the manufacturer's protocol.

\subsection{Glycan Microarray}

The sugar-binding specificities of the mutated PNA proteins were analyzed using a glycan microarray (version 4.2) [46]. Briefly, $100 \mu \mathrm{L}$ of mutated PNA-Fc fusion protein $(50 \mu \mathrm{g} / \mathrm{mL})$ was loaded onto the glycan microarray and incubated at $20{ }^{\circ} \mathrm{C}$ for $18 \mathrm{~h}$. After washing with probing buffer (10 mM Tris-HCl (pH 7.4) containing $0.15 \mathrm{M} \mathrm{NaCl}$ and $0.02 \%$ Tween 20), $100 \mu \mathrm{L}$ of Cy3-labeled donkey anti-human IgG-Fc $\gamma$ antibody $(1 \mu \mathrm{g} / \mathrm{mL}$; Jackson ImmunoResearch, West Grove, PA, USA) in probing buffer was applied to the microarray and incubated at $20{ }^{\circ} \mathrm{C}$ for $3 \mathrm{~h}$. After a further wash with probing buffer, the binding of mutated PNA-Fc fusion protein was detected using the SC-profiler evanescent field fluorescence-assisted scanner (GP Biosciences Ltd., Yokohama, Japan) in the Cy3 mode.

\section{Conclusions}

We established a method for the efficient expression of leguminous lectin subunits on the surface of mammalian cells without the loss of sugar-binding ability. To evaluate the amino acid sequence, especially in its sugar-binding loops, and the sugar-binding specificity of lectins, we introduced random mutations in the sugar-binding loops of peanut agglutinin, expressed on the surface of mammalian cells, and successfully screened for mutated PNAs with novel sugar-binding specificities. The data demonstrated that sugar-binding loop $\mathrm{C}$ was largely involved in sugar-binding specificity of the lectin and critical amino acid residues associated with sugar-binding activity and specificity were clarified.

\section{Acknowledgments}

We thank Ms. Jinko Murakami and Ms. Kayo Suzuki for help in glycan microarray production. This work was supported by a Grant-in-Aid for Scientific Research from the Ministry of Education, Culture, Sports, Science, and Technology of Japan [grant numbers 24390015 (to Kazuo Yamamoto), 24659026 (to Kazuo Yamamoto), and 25117710 (to Kazuo Yamamoto)]. 


\section{Author Contributions}

Kazuo Yamamoto, Naoki Matsumoto, and Jun Hirabayashi conceived and designed the experiments; Keisuke Soga, Hirohito Abo, Sheng-Ying Qin, Takuya Kyoto, Keiko Hiemori, Hiroaki Tateno, and Jun Hirabayashi performed the experiments; Keisuke Soga and Hirohito Abo analyzed the data; Keisuke Soga, Hirohito Abo, Sheng-Ying Qin, and Takuya Kyoto contributed to the reagents, materials and analysis tools; and Kazuo Yamamoto wrote the manuscript.

\section{Conflicts of Interest}

The authors declare no conflict of interest.

\section{Appendix}

\begin{tabular}{|c|c|c|c|c|c|c|c|c|c|}
\hline aFuc & Fuca1-2Gal & Fuca1-3GlcNA & Fuca1-4Glc & GlcNA $\quad H$ type & H type2 & H type3 & A & B & $L e^{a}$ \\
\hline$\triangle$ & $q$ & $\nabla$ & $\Delta \rightarrow$ & o & 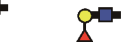 & $q^{\square}$ & वर्य & ol & $\overrightarrow{0}$ \\
\hline$[3 S] \mathrm{Le}^{\mathrm{a}}$ & $\operatorname{Le}^{b}$ & $\operatorname{Le} x$ & $\operatorname{Le}^{y}$ & aNeu5Ac & aNeu5Gc & SA2 & SA3 & 3'SALeC & 3'SL \\
\hline$s^{\Delta} \vec{\sigma}$ & 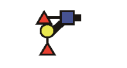 & or & $\underline{7}{ }^{7}$ & $\diamond$ & $\diamond$ & 8 & $\xi$ & of & $\Delta$ \\
\hline 3'SLN & sLea & $s L e^{x}$ & 6'SL & FET & AGP & TF & TG & bGal & {$[3 S] \mathrm{bGal}$} \\
\hline 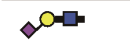 & $\Delta \overrightarrow{0}$ & $\Delta^{\circ}$ & $\theta_{0}$ & Fetuin & $\begin{array}{l}\text { a1-acid } \\
\text { glycoprotein }\end{array}$ & Transferrin & Thyroglobulin & 0 & $s^{a}$ \\
\hline A-di & Lac & $\mathrm{Le}^{\mathrm{C}}$ & {$[3 S] \mathrm{Le}^{\mathrm{C}}$} & LN & [3'S]LN & {$[6 S]$ LN } & {$\left[6^{\prime} S\right] \mathrm{LN}$} & bGalNAc & di-GalNAc \\
\hline$\square^{\circ}$ & $\infty$ & ס & $\sigma^{7}$ & Or & $\mathrm{s}$ & s & son & $\square$ & ط \\
\hline LDN & GA2 Asia & ialo-FET Asial & lo-AGP & Asialo-TF As & Asialo-TG bG & oGlcNAC $[6 \mathrm{~S}] \mathrm{k}$ & bGlcNAc Agala & lacto-FET A & Agalacto-AGP \\
\hline$\sigma^{r}$ & [م-Gal & $\begin{array}{l}\text { alactosylated Gala } \\
\text { FET }\end{array}$ & $\begin{array}{l}\text { lactosylated } G \\
\text { AGP }\end{array}$ & $\begin{array}{l}\text { Galactosylated } \\
\mathrm{TF}\end{array}$ & $\begin{array}{c}\text { Galactosylated } \\
\text { TG }\end{array}$ & d & Agalact & $\begin{array}{l}\text { actosylated Ac } \\
\text { FET }\end{array}$ & $\begin{array}{l}\text { Agalactosylated } \\
\text { AGP }\end{array}$ \\
\hline Agalacto-TF & OVM & OVA & aMan & bMan & [6P]Man & INV & Tn & Core1 $(\mathrm{T})$ & Core2 \\
\hline $\begin{array}{l}\text { Agalactosylated } \\
\text { TF }\end{array}$ & Ovomucoic & Ovalbumin & 0 & O & ${ }^{\mathrm{PO}}$ & Invertase & 마 & 占 & \\
\hline Core3 & Core4 & Core5 & Core6 & Core8 & [3S]core1 & Galb-core3 & Asialo-BSM & Asialo-GP & STn \\
\hline - & & $\square^{\mathbf{a}}$ & ? & م & $\sigma^{b}$ & مי & $\begin{array}{l}\text { Asialo bovine } \\
\text { submaxillary } \\
\text { mucin }\end{array}$ & $\begin{array}{c}\text { Asialo } \\
\text { glycophorin }\end{array}$ & $\vartheta_{\square}$ \\
\hline $\operatorname{STn}(\mathrm{Gc})$ & ST & SAa2-6core1 & BSM & GP & aGal & Gala1-2Gal & Gala1-3Gal G & Gala1-3Lac & Gala1-3LN \\
\hline$\vartheta_{\square}$ & ما & 2 & $\begin{array}{c}\text { bovine } \\
\text { submaxillary } \\
\text { mucin }\end{array}$ & glycophorin & 0 & Q & a & م- & $\infty$ \\
\hline Gala1-4LN & Melibiose & aGlc & bGlc & Maltose & HA & CSA & CSB & HS & HP \\
\hline$\infty$ & $g_{0}$ & o & a & - & $\begin{array}{l}\text { Hyaluronic } \\
\text { acid }\end{array}$ & $\begin{array}{l}\text { Chondoroitin } \\
\text { sulfate A }\end{array}$ & $\begin{array}{l}\text { Chondoroitin } \\
\text { sulfate B }\end{array}$ & $\begin{array}{l}\text { Heparan } \\
\text { sulfate }\end{array}$ & Heparin \\
\hline KS & aRha & Mannan(SC) & Mannan(CA & A) Zymosan & Chitobiose & BSA & PAA & & \\
\hline $\begin{array}{l}\text { Keratan } \\
\text { sulfate }\end{array}$ & Rhamnose & $\begin{array}{l}\text { Saccharomyces } \\
\text { cerevisiae } \\
\text { mannan }\end{array}$ & $\begin{array}{l}\text { Candida } \\
\text { albicans } \\
\text { mannan }\end{array}$ & Zymosan & 무 & BSA & Polyacrylamide & & \\
\hline
\end{tabular}

\begin{tabular}{llllllll|}
\hline Glc & $\circ$ & Fuc & $\Delta$ & Phospho & $\mathbf{P}$ & \\
Man & 0 & NeuAc & $\diamond$ & a-linkage & - & & \\
Gal & 0 & NeuGc & $\diamond$ & $\beta$-linkage & - & & \\
GlcNAc & $\square$ & Sulfo & s & & & & \\
GalNAc & $\square$ & & & & & & \\
\hline
\end{tabular}

Figure A1. Structures of polyacrylamide-based oligosaccharides and glycoproteins used for the glycan microarray analysis. 

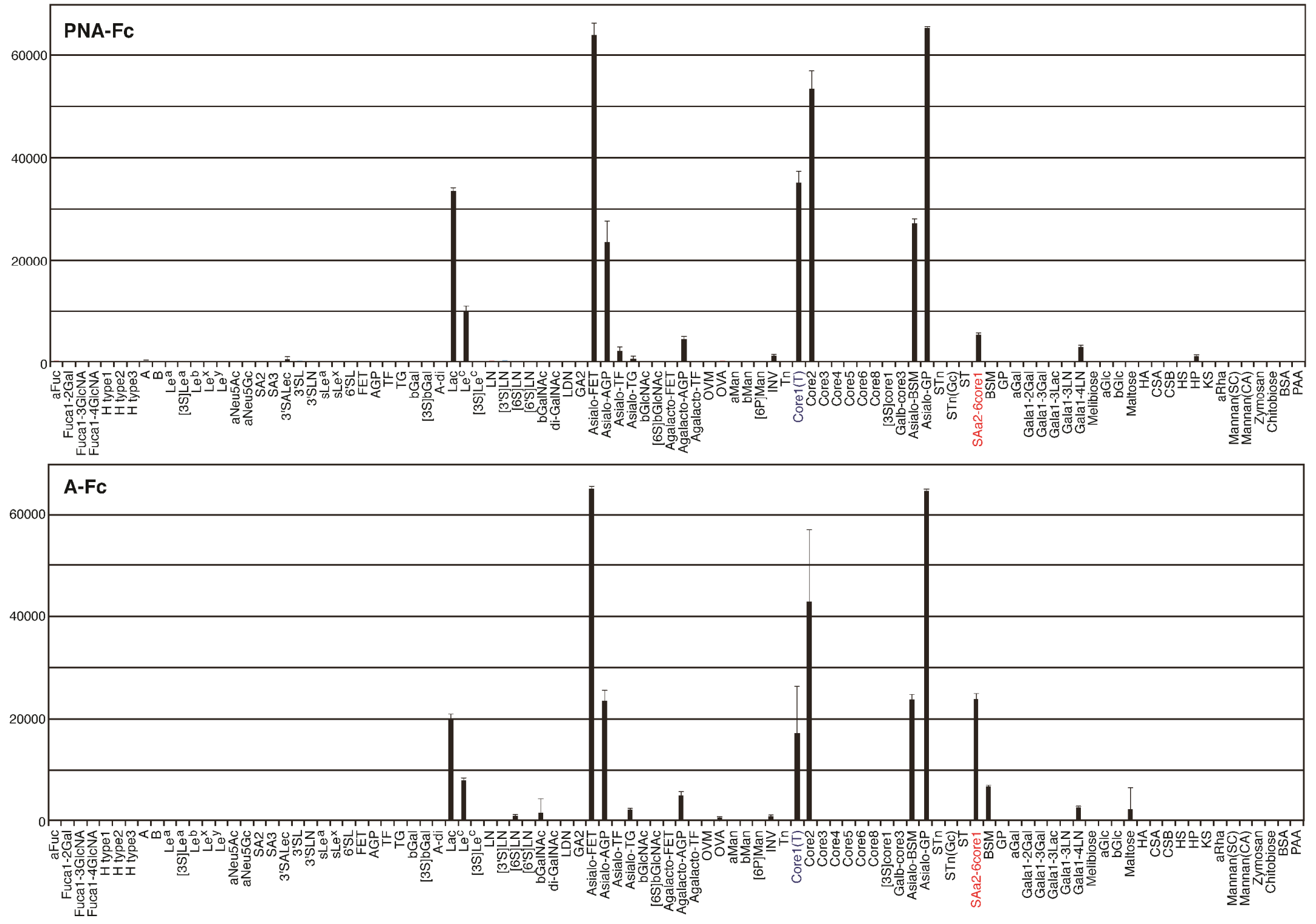

Figure A2. Cont. 

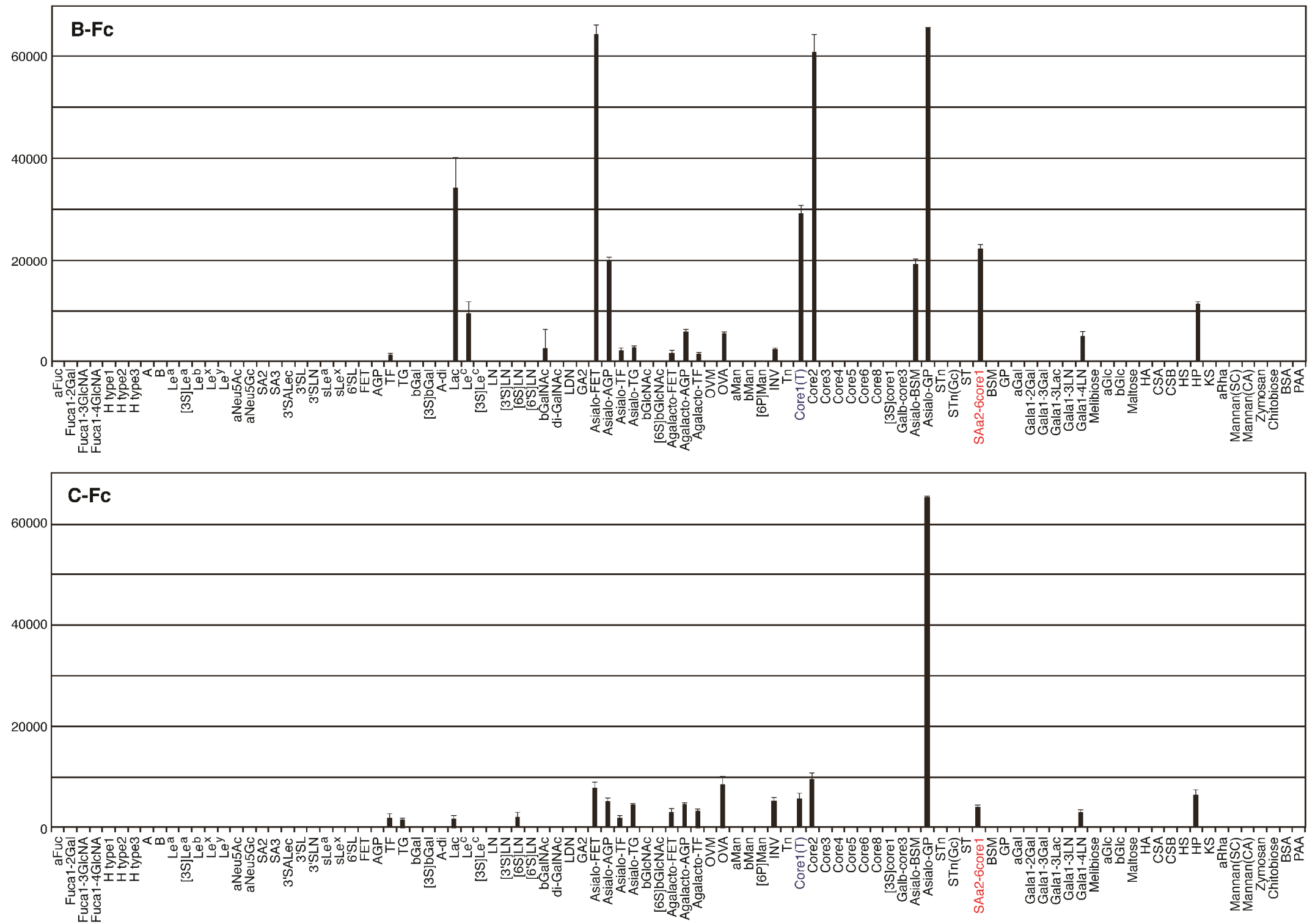

Figure A2. Glycan microarray analysis of wild-type and mutated PNA-IgG Fc fusion proteins. 


\section{References}

1. Jang-Lee, J.; North, S.J.; Sutton-Smith, M.; Goldberg, D.; Panico, M.; Morris, H.; Haslam, S.; Dell, A. Glycomic profiling of cells and tissues by mass spectrometry: Fingerprinting and sequencing methodologies. Methods Enzymol. 2006, 415, 59-86.

2. Pilobello, K.T.; Slawek, D.E.; Mahal, L.K. A ratiometric lectin microarray approach to analysis of the dynamic mammalian glycome. Proc. Natl. Acad. Sci. USA 2007, 104, 11534-11539.

3. Hirabayashi, J.; Yamada, M.; Kuno, A.; Tateno, H. Lectin microarrays: Concept, principle and applications. Chem. Soc. Rev. 2013, 42, 4443-4458.

4. Gupta, G.; Surolia, A.; Sampathkumar, S.G. Lectin microarrays for glycomic analysis. Omics J. Integr. Biol. 2010, 14, 419-436.

5. Katrlík, J.; Svitel, J.; Gemeiner, P.; Kozár, T.; Tkac, J. Glycan and lectin microarrays for glycomics and medicinal applications. Med. Res. Rev. 2010, 30, 394-418.

6. Sharon, N.; Lis, H. Lectins, 2nd ed.; Kluwer: Dordrecht, The Netherlands, 1993; pp. 105-117.

7. Yamamoto, K.; Konami, Y.; Osawa, T. Purification and characterization of a carbohydrate-binding peptide from Bauhinia purpurea lectin. FEBS Lett. 1991, 281, 258-262.

8. Konami, Y.; Yamamoto, K.; Osawa, T.; Irimura, T. Correlation between carbohydrate-binding specificity and amino acid sequence of carbohydrate-binding regions of Cytisus-type anti-H(O) lectins. FEBS Lett. 1992, 304, 129-135.

9. Yamamoto, K.; Konami, Y.; Osawa, T.; Irimura, T. Carbohydrate-binding peptides from several anti-H(O) lectins. J. Biochem. 1992, 111, 436-439.

10. Yamamoto, K.; Konami, Y.; Osawa, T. A chimeric lectin formed from Bauhinia purpurea lectin and Lens culinaris lectin recognizes a unique carbohydrate structure. J. Biochem. 2000, 127, 129-135.

11. Hu, D.; Tateno, H.; Hirabayashi, J. Lectin engineering, a molecular evolutionary approach to expanding the lectin utilities. Molecules 2015, 20, 7637-7656.

12. Yau, T.; Dan, X.; Ng, C.C.W.; Ng, T.B. Lectins with potential for anti-cancer therapy. Molecules 2015, 20, 3791-3810.

13. Fang, E.F.; Zhang, C.Z.Y.; Ng, T.B.; Wong, J.H.; Pan, W.L.; Ye, X.J.; Chan, Y.S.; Fong, W.P. Momordica charantia lectin, a type II ribosome inactivating protein, exhibits antitumor activity toward human nasopharyngeal carcinoma cells in vitro and in vivo. Cancer Prev. Res. 2012, 5, 109-121.

14. Sharon, N.; Lis, H. Legume lectins: A large family of homologous proteins. FASEB J. 1990, 4, 3198-3208.

15. Yamamoto, K.; Konami, Y.; Osawa, T.; Irimura, T. Alteration of the carbohydrate-binding specificity of the Bauhinia purpurea lectin through the preparation of a chimeric lectin. J. Biochem. 1992, 111, 87-90.

16. Loris, R.; Hamelryck, T.; Bouckaert, J.; Wyns, L. Legume lectin structure. Biochim. Biophys. Acta 1998, 1383, 9-36.

17. Sharma, V.; Surolia, A. Analyses of carbohydrate recognition by legume lectins: Size of the combining site loops and their primary specificity. J. Mol. Biol. 1997, 267, 433-445.

18. Pereira, M.E.; Kabat, E.A.; Lotan, R.; Sharon, N. Immunochemical studies on the specificity of the peanut (Arachis hypogaea) agglutinin. Carbohydr. Res. 1976, 51, 107-118. 
19. Lotan, R.; Skutelsky, E.; Danon, D.; Sharon, N. The purification, composition, and specificity of the anti-T lectin from peanut (Arachis hypogaea). J. Biol. Chem. 1975, 250, 8518-8523.

20. Reddi, A.L.; Sankaranarayanan, K.; Arulraj, H.S.; Devaraj, N.; Devaraj, H. Enzyme-linked PNA lectin-binding assay of serum T-antigen in patients with SCC of the uterine cervix. Cancer Lett. 2000, 149, 207-211.

21. Zebda, N.; Bailly, M.; Brown, S.; Dore, J.F.; Berthier-Vergnes, O. Expression of PNA-binding sites on specific glycoproteins by human melanoma cells is associated with a high metastatic potential. J. Cell. Biochem. 1994, 54, 161-173.

22. Priatel, J.J.; Chui, D.; Hiraoka, N.; Simmons, C.J.; Richardson, K.B.; Page, D.M.; Fukuda, M.; Varki, N.M.; Marth, J.D. The ST3Gal-I sialyltransferase controls CD8 ${ }^{+}$T lymphocyte homeostasis by modulating $O$-glycan biosynthesis. Immunity 2000, 12, 273-283.

23. Valenzuela, H.F.; Pace, K.E.; Cabrera, P.V.; White, R.; Porvari, K.; Kaija, H.; Vihko, P.; Baum, L.G. O-glycosylation regulates LNCaP prostate cancer cell susceptibility to apoptosis induced by galectin-1. Cancer Res. 2007, 67, 6155-6162.

24. Tsuji, T.; Yamamoto, K.; Konami, Y.; Irimura, T.; Osawa, T. Separation of acidic oligosaccharides by liquid chromatography: Application to analysis of sugar chains of glycoproteins. Carbohydr. Res. 1982, 109, 259-269.

25. Zhu, K.; Bressan, R.A.; Hasegawa, P.M.; Murdock, L.L. Identification of $N$-acetylglucosamine binding residues in Griffonia simplicifolia lectin II. FEBS Lett. 1996, 390, 271-274.

26. Adar, R.; Sharon, N. Mutational studies of the amino acid residues in the combining site of Erythrina corallodendron lectin. Eur. J. Biochem. 1996, 239, 668-674.

27. Van Eijsden, R.R.; Hoedemaeker, F.J.; Diaz, C.L.; Lugtenberg, B.J.; de Pater, B.S.; Kijne, J.W. Mutational analysis of pea lectin. Substitution of Asn125 for Asp in the monosaccharide-binding site eliminates mannose/glucose-binding activity. Plant. Mol. Biol. 1992, 20, 1049-1058.

28. Samyn-Petit, B.; Krzewinski-Recchi, M.A.; Steelant, W.F.; Delannoy, P.; Harduin-Lepers, A. Molecular cloning and functional expression of human ST6GalNAc II. Molecular expression in various human cultured cells. Biochim. Biophys. Acta 2000, 1474, 201-211.

29. Natchiar, S.K.; Srinivas, O.; Mitra, N.; Surolia, A.; Jayaraman, N.; Vijayan, M. Structural studies on peanut lectin complexed with disaccharides involving different linkages: Further insights into the structure and interactions of the lectin. Acta Cryst. 2006, D62, 1413-1421.

30. Yamamoto, K.; Maruyama, I.N.; Osawa, T. Cyborg lectins: Novel leguminous lectins with unique specificities. J. Biochem. 2000, 127, 137-142.

31. Yabe, R.; Suzuki, R.; Kuno, A.; Fujimoto, Z.; Jigami, Y.; Hirabayashi, J. Tailoring a novel sialic acid-binding lectin from a ricin-B chain-like galactose-binding protein by natural evolution-mimicry. J. Biochem. 2007, 141, 389-399.

32. Hu, D.; Tateno, H.; Kuno, A.; Yabe, R.; Hirabayashi, J. Directed evolution of lectins with sugar-binding specificity for 6-sulfo-galactose. J. Biol. Chem. 2012, 287, 20313-20320.

33. Deantonio, C.; Cotella, D.; Macor, P.; Santoro, C.; Sblattero, D. Phage display technology for human monoclonal antibodies. Methods Mol. Biol. 2014, 1060, 277-295.

34. Hu, D.; Tateno, H.; Hirabayashi, J. Directed evolution of lectins by an improved error-prone PCR and ribosome display method. Methods Mol. Biol. 2014, 1200, 527-538. 
35. Edwards, B.M.; He, M. Evolution of antibodies in vitro by ribosome display. Methods Mol. Biol. 2012, 907, 281-292.

36. Umiel, T.; Daley, J.F.; Bhan, A.K.; Levey, R.H.; Schlossman, S.F.; Reinherz, E.L. Acquisition of immune competence by a subset of human cortical thymocytes expressing mature $\mathrm{T}$ cell antigens. J. Immunol. 1982, 129, 1054-1060.

37. Fukuda, M. Leukosialin, a major $O$-glycan-containing sialoglycoprotein defining leukocyte differentiation and malignancy. Glycobiology 1991, 1, 347-356.

38. Konami, Y.; Yamamoto, K.; Osawa, T.; Irimura, T. Strong affinity of Maackia amurensis hemagglutinin (MAH) for sialic acid-containing Ser/Thr-linked carbohydrate chains of $N$-terminal octapeptides from human glycophorin A. FEBS Lett. 1994, 342, 334-338.

39. Konami, Y.; Ishida, C.; Yamamoto, K.; Osawa, T.; Irimura, T. A unique amino acid sequence involved in the putative carbohydrate-binding domain of a legume lectin specific for sialylated carbohydrate chains: Primary sequence determination of Maackia amurensis hemagglutinin (MAH). J. Biochem. 1994, 115, 767-777.

40. Yamamoto, K.; Konami, Y.; Irimura, T. Sialic acid-binding motif of Maackia amurensis lectins. J. Biochem. 1997, 121, 756-761.

41. Imberty, A.; Gautier, C.; Lescar, J.; Perez, S.; Wyns, L.; Loris, R. An unusual carbohydrate binding site revealed by the structures of two Maackia amurensis lectins complexed with sialic acid-containing oligosaccharides. J. Biol. Chem. 2000, 275, 17541-17548.

42. Ohtsuka, M.; Arase, H.; Takeuchi, A.; Yamasaki, S.; Shiina, R.; Suenaga, T.; Sakurai, D.; Yokosuka, T.; Arase, N.; Iwashima, M.; et al. NFAM1, an immunoreceptor tyrosine-based activation motif-bearing molecule that regulates B cell development and signaling. Proc. Natl. Acad. Sci. USA 2004, 101, 8126-8131.

43. Morita, S.; Kojima, T.; Kitamura, T. Plat-E: An efficient and stable system for transient packaging of retroviruses. Gene Therapy 2000, 7, 1063-1066.

44. Young, N.M.; Johnston, R.A.; Watson, D.C. The amino acid sequence of peanut agglutinin. Eur. J. Biochem. 1991, 196, 631-637.

45. Niwa, H.; Yamamura, K.; Miyazaki, J. Efficient selection for high-expression transfectants with a novel eukaryotic vector. Gene 1991, 108, 193-199.

46. Tateno, H.; Mori, A.; Uchiyama, N.; Yabe, R.; Iwaki, J.; Shikanai, T.; Angata, T.; Narimatsu, H.; Hirabayashi, J. Glycoconjugate microarray based on an evanescent-field fluorescence-assisted detection principle for investigation of glycan-binding proteins. Glycobiology 2008, 18, 789-798.

(C) 2015 by the authors; licensee MDPI, Basel, Switzerland. This article is an open access article distributed under the terms and conditions of the Creative Commons Attribution license (http://creativecommons.org/licenses/by/4.0/). 